\title{
New Insights into the Coordination Chemistry and Molecular Structure of Copper(II) Histidine Complexes in Aqueous Solutions
}

\author{
J. Gerbrand Mesu, ${ }^{\dagger}$ Tom Visser, ${ }^{\dagger}$ Fouad Soulimani, ${ }^{\dagger}$ Ernst E. van Faassen, ${ }^{\ddagger}$ Peter de Peinder, ${ }^{\S}$ \\ Andrew M. Beale, ${ }^{\dagger}$ and Bert M. Weckhuysen ${ }^{*}, \dagger$ \\ Department of Inorganic Chemistry and Catalysis and Interface Physics, Debije Institute, Utrecht \\ University, Sorbonnelaan 16, 3584CA Utrecht, The Netherlands, and Vibspec, Haaftenlaan 28, \\ 4006 XL Tiel, The Netherlands
}

Received August 2, 2005

\begin{abstract}
Aqueous solutions of $\mathrm{Cu}^{2+} /$ histidine (his) (1:2) have been analyzed in parallel with infrared, Raman, ultraviolet/ visible/near-infrared, electron spin resonance, and X-ray absorption spectroscopy in the $\mathrm{pH}$ range from 0 to 10 . Comprehensive interpretation of the data has been used to extract complementary structural information in order to determine the relative abundance of the different complexes. The formation of six different, partly coexisting species is proposed. Structural proposals from literature have been unambiguously confirmed, refined, or, in several cases, corrected. At highly acidic conditions, $\mathrm{Cu}^{2+}$ and his are present as free ions, but around $\mathrm{pH}=2$, coordination starts via the deprotonated carboxylic acid group. This results in the intermediate species $\mathrm{Cu}^{2+}\left[\mathrm{H}_{3} \mathrm{his}^{+}\left(\mathrm{O}_{\mathrm{c}}\right)\right]$ and $\mathrm{Cu}^{2+}\left[\mathrm{H}_{3} \mathrm{his}^{+}\left(\mathrm{O}_{\mathrm{c}}\right)\right]_{2}$. The coordination via $\mathrm{O}_{\mathrm{c}}$ is attended with a drop in the $\mathrm{p} K_{\mathrm{a}}$ value of the other receptor groups resulting in a concomitant conversion to the bidentates $\mathrm{Cu}^{2+}\left[\mathrm{H}_{2}\right.$ his $\left.{ }^{0}\left(\mathrm{O}_{c}, \mathrm{~N}_{\mathrm{am}}\right)\right]$ and $\mathrm{Cu}^{2+}\left[\mathrm{H}_{2} \text { his }{ }^{0}\left(\mathrm{O}_{c}, \mathrm{~N}_{\mathrm{am}}\right)\right]_{2}$, with the latter being dominant at $\mathrm{pH}=3.5$. Coordination of the imidazole ring begins around $\mathrm{pH}=3$ and leads to the formation of the mixed ligand complexes $\mathrm{Cu}^{2+}\left[\mathrm{H}_{2} \mathrm{his}^{0}\left(\mathrm{O}_{c}, \mathrm{~N}_{\mathrm{am}}\right)\right]\left[\mathrm{Hhis}^{-}\left(\mathrm{O}_{c}, \mathrm{~N}_{\mathrm{am}}, \mathrm{N}_{\mathrm{im}}\right)\right]$ and $\mathrm{Cu}^{2+}\left[\mathrm{Hhis}^{-}\left(\mathrm{N}_{\mathrm{am}}, \mathrm{N}_{\mathrm{im}}\right)\right]-$ $\left[\mathrm{Hhis}^{-}\left(\mathrm{O}_{\mathrm{c}}, \mathrm{N}_{\mathrm{am}}, \mathrm{N}_{\mathrm{im}}\right)\right]$ around $\mathrm{pH}=5$. It is demonstrated that coordination of the imidazole ring occurs predominantly via the $\mathrm{N}^{\pi}$ atom. At pH > 7, the double-tridentate ligand complex $\mathrm{Cu}^{2+}\left[\mathrm{Hhis}^{-}\left(\mathrm{O}_{c}, \mathrm{Nam}_{\mathrm{am}}, \mathrm{N}_{\mathrm{im}}\right)\right]_{2}$ is the major species with the $\mathrm{N}$ atoms in the equatorial plane and the $\mathrm{O}$ atoms in the axial position. This complex decomposes at $\mathrm{pH}>10$ into a copper oxide/hydroxide precipitate. The overall results provide a consistent picture of the mechanism that drives the coordination and complex formation of the $\mathrm{Cu}^{2+} / \mathrm{his}$ system.
\end{abstract}

\section{Introduction}

$\mathrm{Cu}$ is one of the most abundant transition metals present in living systems, and $\mathrm{Cu}^{2+}$ ions are well-known to play a key role in the working mechanism of several important metalloenzymes, such as galactose oxidase and superoxide dismutase. A driving force in the activity of these enzymes is the folding of a peptide, which consists of amino acid side chains, around the $\mathrm{Cu}^{2+}$ cation. Histidine (his) moieties are known to be of major importance in this process because this type of $\mathrm{N}$-coordinating ligand forms fairly stable complexes with the $\mathrm{Cu}$ cation. To unravel the formation processes of these types of enzymes and to find the exact

* To whom correspondence should be addressed. E-mail: b.m.weckhuysen@chem.uu.nl.

$\dagger$ Department of Inorganic Chemistry and Catalysis, Debije Institute, Utrecht University.

$\doteqdot$ Interface Physics, Debije Institute, Utrecht University.

$\S$ Vibspec.

1960 Inorganic Chemistry, Vol. 45, No. 5, 2006 coordination geometry of the $\mathrm{Cu} / \mathrm{his}$ moieties, a lot of research has been conducted in this area, ${ }^{1-17}$ much of which has been summarized in two recent reviews. ${ }^{18,19}$

A wide variety of analytical tools have been applied to obtain this type of information directly from the enzyme systems, but the analyses are often hampered by interference

(1) Sundberg, R. J.; Martin, R. B. Chem. Rev. 1974, 74, 471-517.

(2) Abbaspour A.; Kamyabi, M. A. Anal. Chim. Acta 2004, 512, 257269.

(3) Torreggiani, A.; Tamba, M.; Fini, G. Biopolym. 2000, 57, 149-159.

(4) Wang, D.; Zhao, X.; Vargek, M.; Spiro, T. G. J. Am. Chem. Soc. 2000, 122, 2193-2199.

(5) Caswell, D. S.; Spiro, T. G. J. Am. Chem. Soc. 1986, 108, 64706477.

(6) Carrera, F.; Sanchez-Marcos, E.; Merkling, P. J.; Chaboy, J.; MuòozPáez, A. Inorg. Chem. 2004, 43, 6674-6683.

(7) Arena, G. R.; Cali, R.; Cucinotta, V.; Musumeci, S.; Rizzarelli, E.; Sammartano, S. J. Chem. Soc., Dalton Trans. 1984, 1651-1658.

(8) Glusker, P. J. Adv. Protein Chem. 1991, 1-32.

(9) Hasegawa, K.; Ono, T.; Noguchi, T. J. Phys. Chem. A 2002, 106, 3377-3390.

10.1021/ic051305n CCC: $\$ 33.50$ @ 2006 American Chemical Society Published on Web 02/09/2006 
of the protein matrix. As an alternative, complexes of $\mathrm{Cu}^{2+}$ with amino acid ligands are used as model systems, and this approach is even more interesting because complexes of $\mathrm{Cu}^{2+}$ with his can be used to mimic the working mechanism of $\mathrm{Cu}$ enzymes. Another important motivation to study $\mathrm{Cu}^{2+} /$ his species is their expected role in the development of manmade enzymes via functionalization of inorganic hosts, such as zeolites and clay minerals, with these types of complexes. ${ }^{20-24}$

Elucidation of the coordination geometry of the $\mathrm{Cu}^{2+} / \mathrm{his}$ complexes, however, is not easy, because this amino acid ligand has four potential sites for (de)protonation and thus for metal binding, i.e., the carboxylate group, the primary amino group, and two different $\mathrm{N}$ atoms of the imidazole ring. In principle, each of these sites can be involved in the coordination to $\mathrm{Cu}^{2+}$, which may result in mono-, bi-, or tridentate binding forms. Besides, the state of protonation of the different sites, the manner of coordination, and the coexistence of several different complexes are all $\mathrm{pH}$ dependent. Furthermore, the $\mathrm{Cu} /$ his ratio, the $\mathrm{Cu}^{2+}$ concentration, and the ionic strength of the solution are generally known to affect the structures of the complexes. To elucidate the molecular structures of $\mathrm{Cu}^{2+} /$ his complexes and to obtain insight into the forces that drive anchoring of the metal ion, many studies have been carried out since the late 1960s. In these studies, a wide variety of techniques have been used to obtain the desired information, ranging from spectroscopic techniques, like circular dichroism, ${ }^{10,25,26}$ ultraviolet/visible/ near-infrared (UV/vis/NIR), ${ }^{10,25-29}$ infrared (IR), ${ }^{3,14,26-33}$

(10) Casolaro, M.; Chelli, M.; Ginanneschi, M.; Laschi, F.; Muniz-Miranda, M.; Papini, A. M.; Sbrana, G. Spectrochim. Acta A 1999, 55, 16751689.

(11) Doran, M. A.; Chabarek, S.; Martell, A. E. J. Am. Chem. Soc. 1964, 86, 2129-2135.

(12) Larsen, R. W.; Nunez, D. J.; Morgan, W. T.; Muhoberac, B. B.; Ondrias, M. R. Biophys. J. 1992, 1007-1017.

(13) Hashimoto, S.; Takeuchi, H. J. Am. Chem. Soc. 1998, 120, $11012-$ 11013.

(14) Gao, S. L.; Chen, S.; Liu, H.; Hou, R.; Ji, Q. Russ. J. Gen. Chem. 2004, 74, 371-375.

(15) Miura, T.; Hori-i, A.; Mototani, H.; Takeuchi, H. Biochemistry 1999, 38, 11560-11569.

(16) Miura, T.; Satoh, T.; Hori-i, A.; Takeuchi, H. J. Raman Spectrosc. 1998, 29, 41-47.

(17) Zhao, X.; Wang, D.; Spiro, T. G. Inorg. Chem. 1998, 37, 5414-5420.

(18) Sarkar, B. Chem. Rev. 1999, 99, 2535-2544.

(19) Deschamps, P.; Kulkarrui, P. P.; Gautam-Basak, M.; Sarkar, B. Coord. Chem. Rev. 2005, 249, 895-909.

(20) Grommen, R.; Manikandan, P.; Gao, Y.; Shane, T.; Shane, J. J.; Schoonheydt, R. A.; Weckhuysen, B. M.; Goldfarb, D. J. Am. Chem. Soc. 2000, 122, 11488-11496.

(21) Fu, L.; Weckhuysen, B. M.; Verberckmoes, A. A.; Schoonheydt, R. A. Clay Miner. 1996, 31, 491-500.

(22) Mesu, J. G.; Baute, D.; Tromp, H. J.; van Faassen, E. E.; Weckhuysen, B. M. Stud. Surf. Sci. Catal. 2002, 143, 287-293.

(23) Weckhuysen, B. M.; Verberckmoes, A. A.; Fu, L.; Schoonheydt, R. A. J. Phys. Chem. 1996, 100, 9456-9461.

(24) Weckhuysen, B. M.; Verberckmoes, A. A.; Vannijvel, I. P.; Pelgrims, J. A.; Buskens, P. L.; Jacobs, P. A.; Schoonheydt, R. A. Angew. Chem., Int. Ed. Engl. 1995, 34, 2652-2654.

(25) Wellman, K. M.; Wong, B.-K. Proc. Natl. Acad. Sci. 1969, 64, 824827.

(26) Casella, L.; Gulotti, M. J. Inorg. Biochem. 1983, 18, 19-31.

(27) Goodman, B. A.; McPhail, D. B.; Powell, H. K. J. J. Chem. Soc., Dalton Trans. 1980, 822-827.

(28) Prenesti, E.; Berto, S. J. Inorg. Biochem. 2002, 88, 37-43.

(29) Kruck, T. P. A.; Sarkar, B. Can. J. Chem. 1973, 51, 3549-3554.

(30) Sarkar, B.; Wigfield, Y. J. Biol. Chem. 1967, 242, 5572-5577.
Raman, ${ }^{3-5,10,13,15-17,33-35}{ }^{1} \mathrm{H}$ NMR, ${ }^{10,32,36-39}{ }^{13} \mathrm{C}$ NMR, ${ }^{36}$ electron spin resonance (ESR), ${ }^{10,27,37,40-48}$ and extended X-ray absorption fine structure (EXAFS), ${ }^{6,49}$ to potentiometric $^{10,26,28,50-54}$ and calorimetric ${ }^{55}$ experiments.

Several $\mathrm{Cu}^{2+} /$ his complexes consisting of one or two central $\mathrm{Cu}$ atoms have been proposed in these studies, with one or two his ligands in a mono-, bi-, or tridentate coordination and neutrally, negatively, or positively charged. However, despite all of these efforts, controversy on the mode of his binding to $\mathrm{Cu}^{2+}$ and the geometrical structure of the different complexes still exists. As an example, a point of dispute is that $\mathrm{Cu}^{2+}$ prefers a square-planar or highly distorted octahedral configuration, which would exclude coordination via more than two binding sites of the same his molecule. ${ }^{31,54}$ Furthermore, Itabashi and Itoh $^{34}$ reported the existence of four different species and stated that $\mathrm{Cu}^{2+}$ is bound predominantly as a glycine (gly)-like chelate via the deprotonated $\mathrm{NH}_{2}$ group and the carboxylate group. In contrast, Kruck and Sarkar $^{29}$ suggested eight different complexes, of which several involve coordination of the imidazole $\mathrm{N}$ atoms.

A major cause for the conflicting views is that conclusions are often based on only one or two characterization techniques, occasionally combined with theoretical calculations. Moreover, the corresponding experimental conditions are usually different because they have been optimized for a specific characterization technique. To mention a few

(31) Marti, E. M.; Methivier, C.; Dubot, P.; Pradier, C. M. J. Phys. Chem. B 2003, 107, 10785-10792.

(32) Carlson, R. H.; Brown, T. L. Inorg. Chem. 1966, 5, 268-275.

(33) Torreggiani, A.; Tamba, M.; Bonora, S.; Fini, G. Biopolymers 2003 $72,290-298$

(34) Itabashi, M.; Itoh, K. Bull. Chem. Soc. Jpn. 1980, 53, 3131-3137.

(35) Martusevièius, S.; Niaura, G.; Talaikyte, Z.; Razumas, V. Vib. Spectrosc. 1996, 10, 271-280.

(36) Valensin, G.; Basosi, R. J. Inorg. Biochem. 1985, 23, 125-130.

(37) Sigel, H.; McCormick, D. B. J. Am. Chem. Soc. 1971, 93, 20412046.

(38) Sigel, H.; MacKenzie, R. E.; McCormick, D. B. Biochim. Biophys. Acta 1970, 200, 411-413.

(39) Tishmack, P. A.; Bashford, D.; Harms, E.; van Etten, R. L. Biochemistry 1997, 36, 11984-11994.

(40) Epel, B.; Manikandan, P.; Kroneck, P. H. M.; Goldfarb, D. Appl. Magn. Reson. 2001, 21, 287-297.

(41) Manikandan, P.; Epel, B.; Goldfarb, D. Inorg. Chem. 2001, 40, 781787.

(42) Basosi, R.; Valensin, G.; Gaggelli, E.; Froncisz, W.; PasenkiewiczGierula, M.; Antholine, W. E.; Hyde, J. S. Inorg. Chem. 1986, 25, 3006-3010.

(43) Baute, D.; Arieli, D.; Neese, F.; Zimmerman, H.; Weckhuysen, B. M.; Goldfarb, D. J. Am. Chem. Soc. 2004, 126, 11733-11745.

(44) Rotilio, G.; Calabrese, L. Arch. Biochem. Biophys. 1971, 143, $218-$ 225.

(45) Colaneri, M. J.; Peisach, J. J. Am. Chem. Soc. 1992, 114, 5335-5341.

(46) Crawford, T. H.; Dalton, J. O. Arch. Biochem. Biophys. 1969, 131, $123-138$.

(47) Abramenko, V. A.; Bolotin, S. N.; Nikolaienko, I. A. J. Mol. Liq. 2001, 91, 219-222.

(48) Szabo-Planka, T.; Rockenbauer, A.; Korecz, L.; Nay, D. Polyhedron 2000, 19, 1123-1131.

(49) Strange, R. W.; Blackburn, N. J.; Knowles, P. F.; Hasnain, S. S. J. Am. Chem. Soc. 1987, 109, 7157-7162.

(50) Perrin, D. D.; Sharma, V. S. J. Chem. Soc. A 1967, 724-728.

(51) Williams, D. R. J. Chem Soc., Dalton Trans. 1972, 790-797.

(52) Freeman, H. C.; Martin, P. J. Biol. Chem. 1969, 224, 4823-4830.

(53) Meyer, J. L.; Bauman, J. E. J. Am. Chem. Soc. 1970, 92, 4210-4216.

(54) Leberman, R.; Rabin, B. R. Trans. Faraday Soc. 1959, 55, 16601670.

(55) Zhang, Y.; Akilesh, S. Inorg. Chem. 2000, 39, 3057-3064. 
examples, the weak scattering efficiency in Raman spectroscopy requires high $\mathrm{Cu}$ concentrations, whereas the opposite situation is desired in UV/vis/NIR because of the intense blue color of the complexes dissolved in water. On the contrary, IR spectroscopic studies on aqueous systems are largely hampered by the interference of water absorptions. For that reason, the preferred method for this technique is analysis after lyophilization, crystallization, or the use of $\mathrm{D}_{2} \mathrm{O}$. Finally, (pulsed) ESR and electron-nuclear double resonance studies have been carried out on frozen solutions at temperatures even down to $4 \mathrm{~K} \cdot{ }^{20,40,41,43}$ Hence, it is very difficult to compare data and to draw objective and integrated conclusions.

In our opinion, a more successful strategy to gain more insight into the coordination chemistry of $\mathrm{Cu}^{2+} /$ his complexes is to combine several complementary analytical techniques in one integrated approach, which allows analysis at more or less the same sample conditions. To our knowledge, such a multitechnique approach has not been reported for $\mathrm{Cu}^{2+}$ / his complexes so far. Five techniques that, within certain limits, meet the above-mentioned requirements are IR, Raman, UV/vis/NIR, ESR, and X-ray absorption spectroscopy (XAS). As demonstrated in a recent paper, ${ }^{56}$ the integrated use of IR and Raman has proven to be an ideal tool to distinguish all possible states of protonation of his, while UV/vis/NIR is the method of choice to determine the identity and the amount of atoms that are coordinating to the central $\mathrm{Cu}^{2+}$ ion from the $\mathrm{Cu} \mathrm{d}-\mathrm{d}$ transition band. In addition, ESR can be used to discriminate between coordination of $\mathrm{O}$ and $\mathrm{N}$ in the equatorial plane of the complexes. Finally, EXAFS can supply information on the distance between the central $\mathrm{Cu}$ cation and the $\mathrm{O}$ and/or $\mathrm{N}$ atoms in the first coordination sphere and thus on changes in the local structure around the $\mathrm{Cu}^{2+}$ ion. Moreover, an important advantage of these characterization techniques is that they can be applied not only at physiological conditions but also at more extreme $\mathrm{pH}$ values. For that reason, we decided to carry out a systematic study, using this multispectroscopic approach, on $\mathrm{Cu}^{2+}$ /his complexes in aqueous solutions, which covers the widest possible $\mathrm{pH}$ range. As a result, we propose a more consistent picture for the mechanism that drives the complex formation and of the molecular structure of this very important $\mathrm{Cu}^{2+} /$ his system.

\section{Experimental Section}

1. Chemicals and Solutions. All chemicals (p.a. grade) were obtained from Acros Organics (Geel, Belgium). For each experiment, solutions of L-histidine, $\mathrm{Cu}\left(\mathrm{NO}_{3}\right)_{2} \cdot 3 \mathrm{H}_{2} \mathrm{O}$, and $\mathrm{CuCl}_{2}$ (all p.a. grade) were freshly made by dissolving each of the components in demineralized water at various concentrations. All solutions were prepared in $\mathrm{Cu}^{2+}$ /his ratio of $1: 2$ and acidified by the addition of $\mathrm{HCl}$ or made basic by the addition of $\mathrm{NaOH}$ in order to prevent interfering buffer absorption in the IR or Raman spectra. To minimize the reducing effect of the X-ray beam on the samples, $\mathrm{Cu}\left(\mathrm{NO}_{3}\right)_{2} \cdot 3 \mathrm{H}_{2} \mathrm{O}$ was used as the precursor salt instead of $\mathrm{CuCl}_{2}$ and $\mathrm{HNO}_{3}$ was used instead of $\mathrm{HCl}$ to adjust the $\mathrm{pH}$ for the EXAFS

(56) Mesu, J. G.; Visser, T.; Soulimani, F.; Weckhuysen, B. M. Vib. Spectrosc. 2005, 39, 114-125. analyses. ${ }^{57}$ Concentrations were $0.001 \mathrm{M}\left(\mathrm{Cu}^{2+}\right)$ for ESR, $0.01 \mathrm{M}$ for EXAFS and simultaneous UV/vis/NIR, and $0.25 \mathrm{M}$ for IR, Raman, and UV/vis/NIR analyses. IR, Raman, and UV/vis/NIR measurements were carried out simultaneously with the same 0.25 M solutions. Additional UV/vis/NIR analyses of the $0.01 \mathrm{M}$ solutions were performed to detect possible concentration effects and, hence, to facilitate a comparison of the IR and Raman data with the results of the more diluted samples used for EXAFS and ESR. All experiments were done at ambient temperature (298 K), and a pH meter (model PHM 210 from Radiometer Analytical, USA, Loveland, $\mathrm{CO}$ ) was used to determine the $\mathrm{pH}$ values. To establish the stability of the $\mathrm{Cu}^{2+} /$ his complexes and the reversibility of the complexation process, titration experiments were carried out from $\mathrm{pH}=0$ up to $\mathrm{pH}=12$ and backward and from $\mathrm{pH}=0$ up to $\mathrm{pH}=10$ and backward. Both experiments were monitored by IR, Raman, and UV/vis/NIR. Solutions of $\mathrm{Cu}$ with gly and histamine (him) were studied as structural analogues of the $\mathrm{Cu}^{2+}$ / his complex.

2. Characterization. IR measurements during titrations were performed at room temperature on an Autochem ReactIR-4000 system (Mettler Toledo) equipped with a Dicomp attenuated total reflectance probe and a nitrogen-cooled mercury/cadmium/telluride detector. The sample compartment was flushed with dry air to reduce interference from water and carbon dioxide. For each spectrum, 256 scans were accumulated at a data-point resolution of $2 \mathrm{~cm}^{-1}$ (optical resolution of $4 \mathrm{~cm}^{-1}$ ). Spectral interpretation was carried out after subtraction of the spectrum of water at the corresponding $\mathrm{pH}$ as the background. Multivariate curve resolution (MCR) was carried out on the IR spectra, using model calculations in Matlab. Details on the MCR procedure can be found in the Supporting Information.

Raman measurements were carried out on a Kaiser RXN spectrometer equipped with a 70-mW, 532-nm diode laser for excitation, a holographic grating for dispersion, and a Peltier-cooled Andor CCD camera for detection. Scanning was performed via a 10 -mm objective probe head that was mounted just above the surface of the solution. The solution was stirred and kept at room temperature during the measurements to prevent local heating, i.e., degradation of the sample. The detector pixel resolution was about $2 \mathrm{~cm}^{-1}$, and 15 scans were accumulated for one spectrum at an exposure time of $30 \mathrm{~s} / \mathrm{scan}$. Subtraction of the water background has not been applied for the Raman spectra.

$\mathrm{UV} / \mathrm{vis} / \mathrm{NIR}$ spectra of the aqueous solutions were measured from 200 to $1000 \mathrm{~nm}$ at a spectral resolution of $0.15 \mathrm{~nm}$ with a Cary 50 spectrometer (Varian) equipped with a probe head that was connected to the spectrometer via optical fibers. The effective optical path length in the probe head was $2 \mathrm{~mm}$ for the $0.25 \mathrm{M}$ samples, whereas the path length was $10 \mathrm{~mm}$ for the $0.010 \mathrm{M}$ samples.

X-band ESR measurements were carried out on a Bruker ESP300 (Utrecht) and a Bruker ESP300E spectrometer (Leuven), both operating near $9.5 \mathrm{GHz}$. ESR spectra were recorded at room temperature, using $80-\mu \mathrm{L}$ quartz capillaries as sample cells. Spectra were taken at $\mathrm{pH}$ values of 2.0, 2.9, 3.4, 4.4, and 7.3. An in-housedeveloped computer program was used for simulation of the $\mathrm{Cu}^{2+} /$ his spectra, taking into account the natural abundances of the ${ }^{63} \mathrm{Cu}$ $(69.2 \%)$ and ${ }^{65} \mathrm{Cu}(30.8 \%)$ isotopes. The EPR spectra are motionally narrowed and can be described in the Redfield limit as a superposition of Lorentzians because, at room temperature, the $\mathrm{Cu}$ complexes are rapidly tumbling in the solution. For that reason, the spectrum

(57) Mesu, J. G.; van der Eerden, A. M. J.; de Groot, F. M. F.; Weckhuysen, B. M. J. Phys. Chem. B 2005, 109, 4042-4047. 


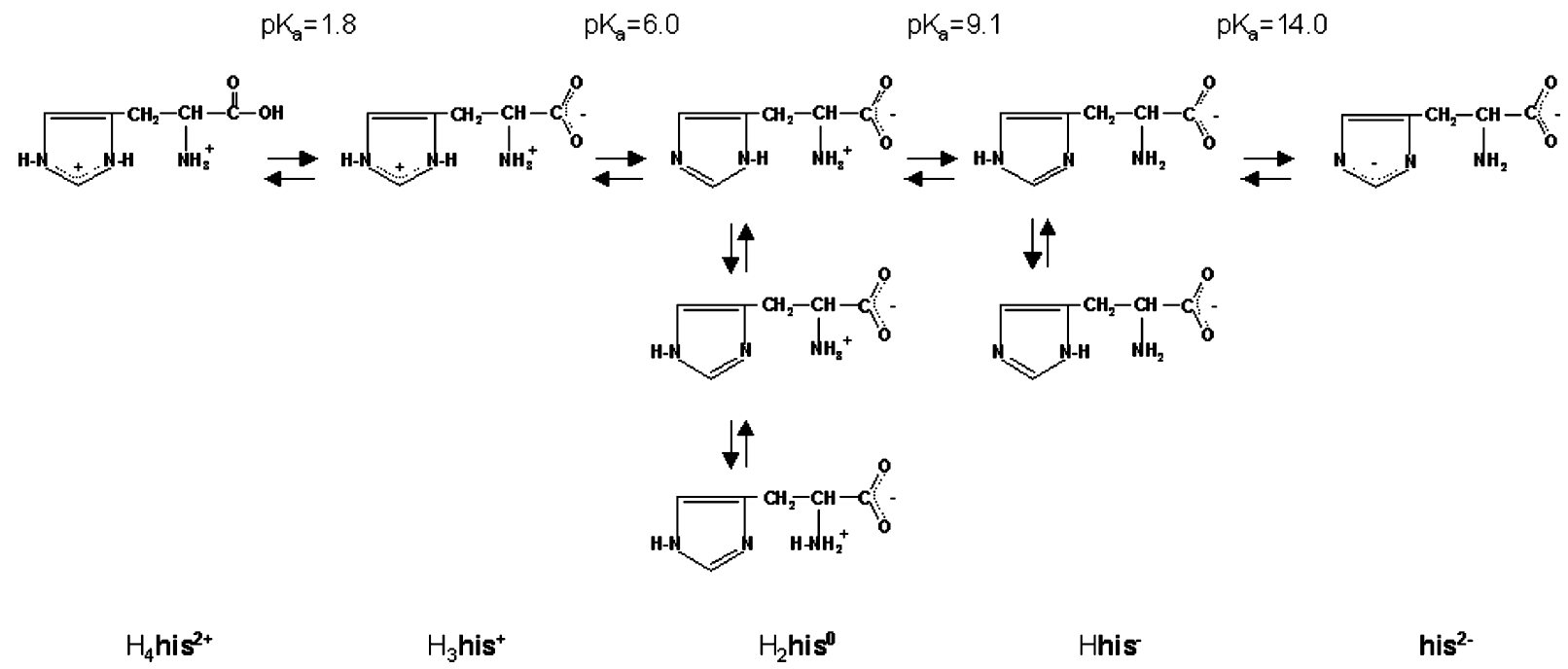

Figure 1. Different states of protonation and corresponding $\mathrm{p} K_{\mathrm{a}}$ values of his.

of each species has been simulated as the weighted superposition of eight Lorentzians, i.e., four from each $\mathrm{Cu}$ isotope $(I=3 / 2)$. The different line widths of the Lorentzians as a result of the difference in the hyperfine quantum number were taken into consideration by fitting the relaxation parameters $\alpha, \beta$, and $\gamma$, according to the formula $T_{2}^{-1}=\alpha+\beta m+\gamma m^{2}$. In this way, the $g$ and $A$ values, together with the relative abundance of the different $\mathrm{Cu}^{2+} / \mathrm{his}$ complexes at various $\mathrm{pHs}$, were determined. To compensate for the difference in the nuclear moments of ${ }^{63} \mathrm{Cu}$ and ${ }^{65} \mathrm{Cu}$, the $A$ values were calculated with $A^{63}=A_{0}$ and $A^{65}=1.07 A_{0}$.

XAS data were collected on Beamline BM26A at the ESRF (Grenoble, France), which operates at $6 \mathrm{GeV}$ with a typical beam current of $200 \mathrm{~mA}$. The station was equipped with an $\mathrm{Si}(111)$ double-crystal monochromator and ion chambers for measuring incident and transmitted beam intensities. Measurements were performed at the $\mathrm{Cu} \mathrm{K}$ edge $(8979 \mathrm{eV})$ in transmission mode on samples at $\mathrm{pH}=2.0,2.9,3.4,4.4,6.0$, and 8.0 at room temperature in a stainless steel cell (diameter of $2.5 \mathrm{~mm}$ ) with Kapton windows. Higher harmonic contributions were filtered by the optics of the setup. A $\mathrm{Cu}$ foil was applied to calibrate the energy of the monochromator. Several scans were averaged to improve the signalto-noise ratio of the data. The XAFS data were processed using the suite of programs available at Daresbury Laboratory, namely, EXCALIB (for converting the raw data to energy versus the absorption coefficient) and EXBROOK (for pre- and post-edge background removal) to obtain the normalized X-ray absorption near-edge structure (XANES) part of the spectra and EXCURV9858 to carry out EXAFS data analysis. EXAFS refinements were carried out on $k^{1}$-weighted spectra plotted over a $k$ range of $3-13.3 \AA^{-1}$, considering only single-scattering paths. An amplitude reduction factor $\left(S_{\mathrm{o}}^{2}\right)$ value of 0.9 obtained from the fitting of the $\mathrm{Cu}$ metal foil was also used in the analyses. Because the $\mathrm{Cu}-\mathrm{O}$ and $\mathrm{Cu}-\mathrm{N}$ bond distances and backscattering amplitudes are about similar, it is difficult to distinguish between their respective contributions in EXAFS. This is a particular problem for the $\mathrm{Cu}^{2+} /$ his system, in which the two different atoms are coordinating in the same coordination shell. Because the fitting of two shells with the respective atoms leads to unphysical results, the refinements were performed considering only a single shell of either $\mathrm{Cu}-\mathrm{O}$ or $\mathrm{Cu}-\mathrm{N}$ contributions, with the best fit to the data being determined by the EXAFS $R$ factor (goodness of fit).

(58) Binsted, N.; Campbell, J. W.; Gurman, S. J.; Stephenson, P. C. EXAFS Analysis Programs; Daresbury Laboratory: Warrington, U.K., 1991.

\section{Results}

As described in a previous paper, ${ }^{56}$ his in an aqueous solution can be present in five different $\mathrm{pH}$-dependent states of protonation, i.e., $\mathrm{H}_{4}$ his $^{2+}, \mathrm{H}_{3}$ his $^{+}, \mathrm{H}_{2}$ his $^{0}$, Hhis ${ }^{-}$, and his ${ }^{2-}$ (Figure 1). The molecule has four potential sites for deprotonation and thus for metal coordination, but metal binding via the deprotonated imidazole ring $\left(\mathrm{his}^{2-}\right)$ is generally rejected regarding the extremely high $\mathrm{p} K_{\mathrm{a}}$ value of this element $\left(\mathrm{p} K_{\mathrm{a}}=14\right)$. Furthermore, the ionic state $\mathrm{H}_{4}$ his $^{2+}$ lacks a site available for coordination and this leaves, in principle, $\mathrm{H}_{3}$ his $^{+}, \mathrm{H}_{2}$ his $^{0}$, and Hhis ${ }^{-}$as possible ligating structures. On the other hand, the presence of two different $\mathrm{N}$ atoms in the imidazole ring also allows $\mathrm{H}_{2}$ his $^{0}$ and Hhis ${ }^{-}$ to be present in two $\mathrm{pH}$-dependent tautomeric forms. The commonly accepted notation to distinguish both $\mathrm{N}$ atoms is $\mathrm{N}^{\pi}$ for the one closest to the $\mathrm{CH}_{2}$ group and $\mathrm{N}^{\tau}$ for the other one. Unfortunately, a uniform nomenclature to describe the different $\mathrm{Cu}^{2+} /$ his complexes is absent in the literature. To prevent further confusion, we define the state of protonation of his as described in Figure 1, while for the different metal binding sites, the following notation is used: $\mathrm{O}_{c}$ for the carboxylate group, $\mathrm{N}_{\mathrm{am}}$ for the amino group, and $\mathrm{N}_{\mathrm{im}}$ for the imidazole $\mathrm{N}$ atoms, which can be denoted in more detail, if appropriate, as $\mathrm{N}^{\pi}$ for the $\mathrm{N}$ closest to the $\mathrm{CH}_{2}$ group and $\mathrm{N}^{\tau}$ for the other one.

Furthermore, it should be noted that at certain $\mathrm{pH}$ values two, three, or even more different complexes could coexist, which implies that spectra will not always correspond to single species. Obviously, this hampers a straightforward interpretation and unambiguous structural elucidation. Spectral subtraction, deconvolution, and difference spectroscopy have been proposed in the literature to partially circumvent this problem, but, in general, these methods were found to be not very successful because of the lack of reliable standards and the large number of factors that may affect band positions and intensities. For those reasons, these methods have not been applied here. Instead, to obtain as much information as possible, titration experiments have been carried out under well-controlled experimental conditions 
Mesu et al.

and, when appropriate, with increments of about $0.1 \mathrm{pH}$ units between two subsequent measurements. As described in the Experimental Section, two different titration experiments were performed to check the reversibility of the complex formation. In the first experiment, the $\mathrm{pH}$ of the $\mathrm{Cu}^{2+} /$ his solution was raised from $\mathrm{pH}=0$ up to $\mathrm{pH}=12$ and back, but we observed precipitation and a change of color of the solution above $\mathrm{pH}=10$. The same observations were reported by Itabashi and Itoh, ${ }^{34}$ and in accordance with these authors, we identified the precipitate as copper oxide/ hydroxide. However, we also noticed that the complex formation process was irreversible when passing $\mathrm{pH}=12$ and the same result was obtained when titration was started at $\mathrm{pH}=12$. Furthermore, precipitation turned out to proceed faster when the solution was not freshly prepared. These phenomena were not observed when a $\mathrm{pH}$ value of 10 was not exceeded, and for that reason, spectral data at $\mathrm{pHs}$ higher than 10 have been rejected. Implicitly, this implies that we also reject the existence of a binuclear $\mathrm{Cu}^{2+} /$ his complex at $\mathrm{pH}>10.5$, as proposed in the literature. ${ }^{29}$

1. Vibrational Spectroscopy. The large number of IR and Raman spectra, recorded during the titration experiments, allowed representation of the data in 3-D plots (see Figure S1 in the Supporting Information). For IR, the resulting picture illustrated the overall changes in the spectra as a function of the $\mathrm{pH}$, but determination of small spectral changes required closer examination of the individual spectra. A similar 3-D representation of the Raman spectra turned out to be less informative because the band intensities drop dramatically at higher $\mathrm{pH}$ as a result of strong darkening of the solution. As an alternative, a number of representative IR and Raman spectra at $\mathrm{pH}$ values of $1,2,4$, and 8 are presented in Figures 2 and 3 (for a more detailed overview of the spectra, we refer to the Supporting Information). Assignments (as indicated in Figures 2 and 3 ) are proposed after spectral interpretation in the Discussion section, taking into account IR and Raman selection rules and assignments from our recent work..$^{56}$ In addition, spectral details, which are relevant to the determination of coordination sites and the geometrical structure of complexes, are presented.

2. UV/Vis/NIR Spectroscopy. The UV/vis/NIR absorption spectra of aqueous $0.01 \mathrm{M} \mathrm{Cu}^{2+} /$ his solutions as a function of the $\mathrm{pH}$ are presented in Figure 4.

According to the literature, the band with $\lambda_{\max }$ between 600 and $800 \mathrm{~nm}$ is assigned to the $\mathrm{d}-\mathrm{d}$ transition of $\mathrm{Cu}^{2+} .59,60$ The intensity of this band increases with the $\mathrm{pH}$, and the position shifts to shorter wavelength up to $\mathrm{pH}=5$, after which it shifts back to longer wavelength for $\mathrm{pH}>5$. The absorption band around $285 \mathrm{~nm}$ increases very strongly with the $\mathrm{pH}$ and shifts to longer wavelength. To determine the origin of the intensity increase and the shift in the position of the $\mathrm{d}-\mathrm{d}$ transition band, the spectra of the $\mathrm{Cu}^{2+} /$ his system were compared with the UV/vis/NIR data of solutions containing $\mathrm{Cu}^{2+}$ complexes with him and gly, recorded over

(59) Gerloch, M.; Constable, E. C. Transition Metal Chemistry; VCH: Weinheim, Germany, 1994.

(60) Lever, A. B. P. Inorganic Electronic Spectroscopy; Elsevier Science BV, Amsterdam, The Netherlands, 1987.

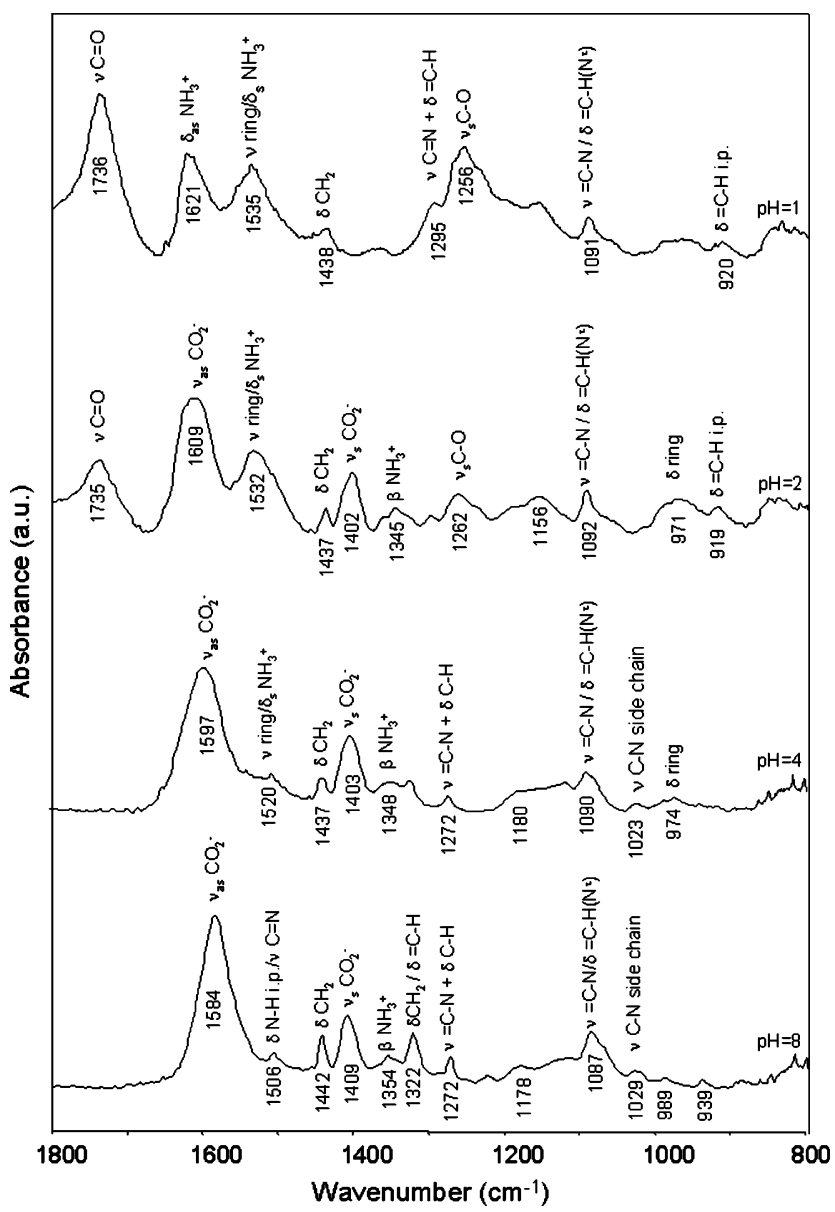

Figure 2. IR spectra of $\mathrm{Cu}^{2+} /$ his solutions at $\mathrm{pH}=1$ (top), $\mathrm{pH}=2, \mathrm{pH}$ $=4$, and $\mathrm{pH}=8$ (bottom). The assignments of the vibrations are indicated in the figure.

the same $\mathrm{pH}$ range. These ligands have been chosen because they have only two coordinating sites, which are highly comparable to the ones of his, i.e., $\mathrm{N}_{\mathrm{am}}$ and $\mathrm{N}_{\mathrm{im}}$ for him and $\mathrm{N}_{\mathrm{am}}$ and $\mathrm{O}_{\mathrm{c}}$ for gly. Besides, the coordination geometry of these $\mathrm{Cu}^{2+}$ complexes is well-known and relatively simple. The peak position of the $\mathrm{d}-\mathrm{d}$ transition band turned out to be the same for all compounds at $\mathrm{pH}=1$ but differ at higher $\mathrm{pH}$ values. Furthermore, all samples exhibit a considerable shift to shorter wavelength, but the band of $\mathrm{Cu}^{2+} /$ his passes a minimum at $\mathrm{pH}=5$, whereas the positions of the $\mathrm{Cu}^{2+}$ / gly and $\mathrm{Cu}^{2+} /$ him solutions stabilize at higher $\mathrm{pH}$ values (see Figure S4 in the Supporting Information). A deviating behavior of $\mathrm{Cu}^{2+} /$ his is also observed for the intensity of the $\mathrm{d}-\mathrm{d}$ transition band as it increases up to $\mathrm{pH}=10$, whereas for $\mathrm{Cu}^{2+} / \mathrm{him}$ and $\mathrm{Cu}^{2+} / \mathrm{gly}$, it remains constant at $\mathrm{pH}>7$. Finally, it should be noted that the data obtained from the $0.01 \mathrm{M} \mathrm{Cu}^{2+} /$ his solutions showed no significant differences compared to the $0.25 \mathrm{M}$ samples.

3. ESR. As was expected for a $\mathrm{Cu}^{2+}(I=3 / 2)$ complex in solution at room temperature, the first-derivative ESR spectra recorded at $\mathrm{pH}$ values of 4.4 and 7.3 (Figure 5) show four hyperfine lines. In contrast, at least five hyperfine lines are distinguished at $\mathrm{pH}=2.0,2.9$, and 3.4, which indicates that more than one $\mathrm{Cu}^{2+} /$ his complex must be present in the corresponding solutions. To determine the ESR parameters of the complexes and their relative contribution, spectrum 


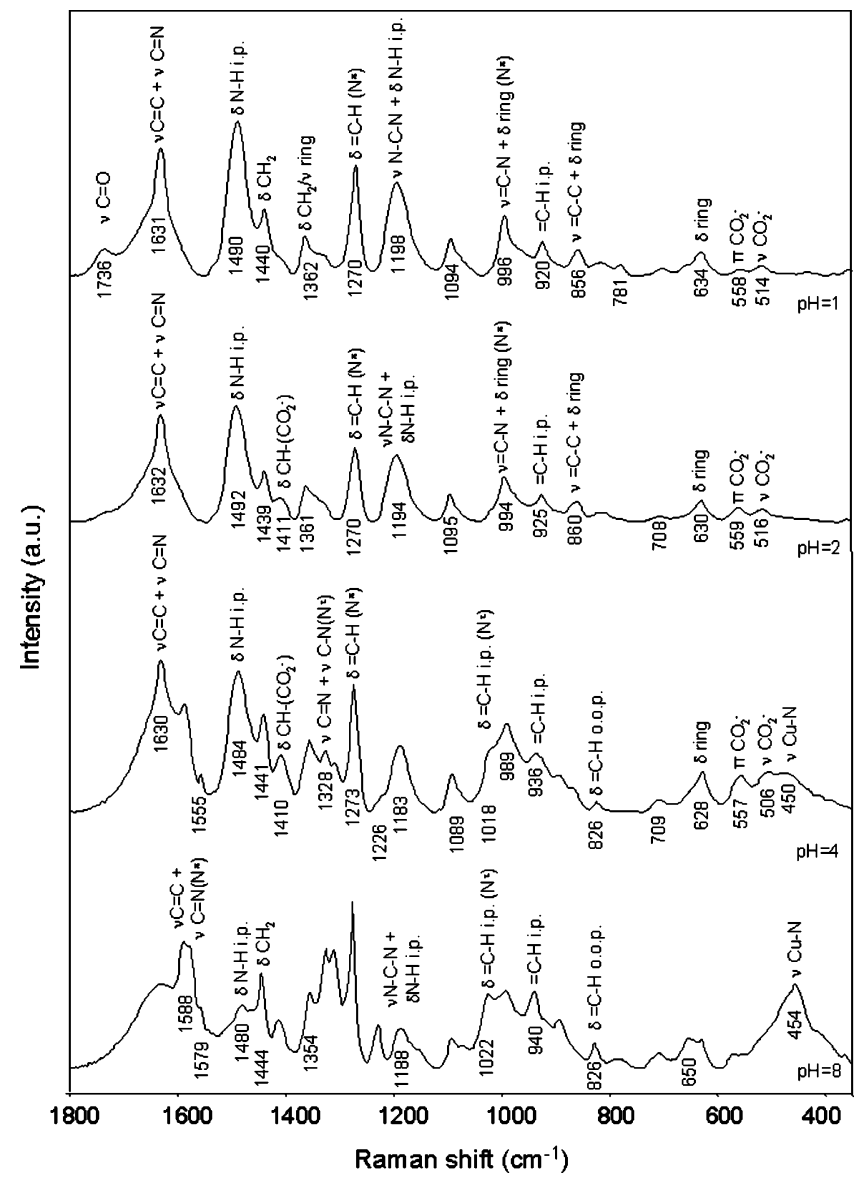

Figure 3. Raman spectra of $\mathrm{Cu}^{2+}$ /his solutions at $\mathrm{pH}=1$ (top), $\mathrm{pH}=2$, $\mathrm{pH}=4$, and $\mathrm{pH}=8$ (bottom). The assignments of the vibrations are indicated in the figure.

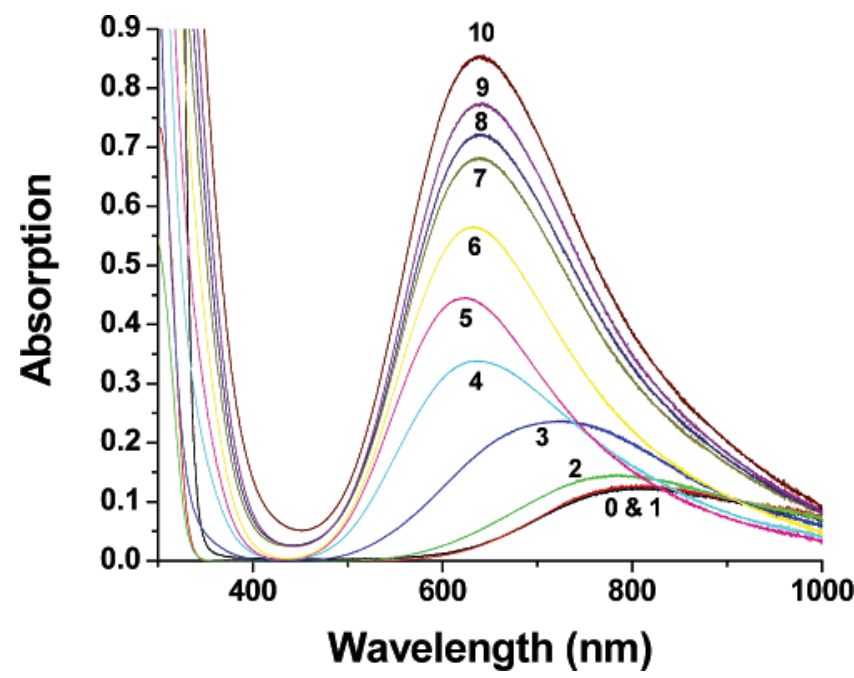

Figure 4. UV/vis/NIR spectra of the $0.01 \mathrm{M} \mathrm{Cu}^{2+} /$ his (1:2) solutions in the $\mathrm{pH}$ range of $0-10(\mathrm{pH}$ values are indicated).

simulations were carried out. The natural abundance of the $\mathrm{Cu}$ isotopes and the different widths of the $\mathrm{Cu}$ hyperfine lines were taken into account upon fitting the relaxation parameters. The results of the calculations obtained for all samples are summarized in Table 1. The results revealed the presence of five different $\mathrm{Cu}^{2+} /$ his complexes in the $\mathrm{pH}$ range of 2.0-7.3 in a relatively large abundance, each of

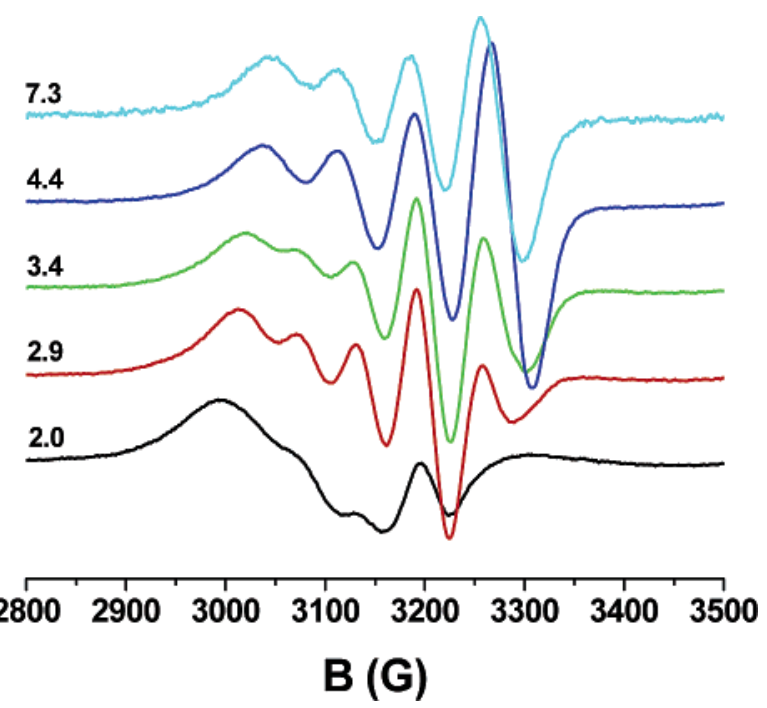

Figure 5. First-derivative ESR spectra of $0.001 \mathrm{M} \mathrm{Cu}^{2+} /$ his solutions at $\mathrm{pH}$ values of $2.0,2.9,3.4,4.4$, and 7.3 .

Table 1. Optimized ESR Parameters Obtained from Simulation of the $\mathrm{Cu}^{2+} /$ his ESR Spectra at Different $\mathrm{pH}$ Values ${ }^{a}$

\begin{tabular}{|c|c|c|c|c|c|c|c|}
\hline $\mathrm{pH}$ & species & $\begin{array}{c}\text { abundance } \\
(\%)\end{array}$ & $g_{0}$ value & $\begin{array}{l}A_{0} \text { value } \\
\text { (G) }\end{array}$ & $\begin{array}{c}\alpha \\
(\mathrm{G})\end{array}$ & $\begin{array}{c}\beta \\
(\mathrm{G})\end{array}$ & $\begin{array}{c}\gamma \\
(\mathrm{G})\end{array}$ \\
\hline \multirow[t]{2}{*}{2.0} & $\mathrm{Cu}^{2+}\left(\mathrm{H}_{2} \mathrm{O}\right)_{6}$ & 85 & 2.193 & 34 & 49 & -1.6 & 0.9 \\
\hline & $\mathrm{c}$ & 15 & 2.154 & 58 & 31 & -8.9 & 1.3 \\
\hline \multirow[t]{2}{*}{2.9} & $\mathrm{c}$ & 75 & 2.154 & 58 & 33 & -6.9 & 2.8 \\
\hline & $\mathrm{e}$ & 25 & 2.126 & 74 & 28 & -10 & 4.2 \\
\hline \multirow[t]{2}{*}{3.4} & $\mathrm{c}$ & 55 & 2.154 & 58 & 31 & -8.9 & 2.3 \\
\hline & $\mathrm{e}$ & 45 & 2. & 74 & 29 & -10 & 2.9 \\
\hline 4.4 & f & 90 & 2.119 & 72 & 30 & -10 & 3.5 \\
\hline 7.3 & $\mathrm{~h}$ & 90 & 2.120 & 64 & 31 & -10 & 2.6 \\
\hline
\end{tabular}

${ }^{a}$ Details on the simulation procedure are given in the Experimental Section. The species indicated as c, e, f, and $\mathrm{h}$ refer to the structures as depicted in Figure 7. Estimated overall accuracies: abundance, 10\%; $g_{0}$ value, $0.002 ; A_{0}$ value, $2 \mathrm{G} ; \alpha, 2 \mathrm{G} ; \beta, 1 \mathrm{G} ; \gamma, 0.5 \mathrm{G}$.

them characterized by their own $g_{0}$ and $A_{0}$ values. A rough estimate of the relative contribution of these species is also included in Table 1. Occasionally, different values have been obtained for the same species at different pHs. This reflects the inaccuracy of the simulation and is probably due to differences in the physical properties of the solution $(\mathrm{pH}$, viscosity, and dielectric constant).

4. EXAFS Analysis. The XANES of the XAS spectra of four $\mathrm{Cu}^{2+} /$ his samples, the background-subtracted EXAFS data $\left(k^{1}\right.$-weighted) at various $\mathrm{pHs}$, and the associated Fourier transforms (including both the real part and the transform envelope) are presented in the Supporting Information (Figures S6-S8). The results of the fitting are presented in the Supporting Information (Table S1). From the analyses, it can be concluded that the bond distance sequence as a function of the $\mathrm{pH}$ is as follows: $\mathrm{pH}=2.0 \approx \mathrm{pH}=2.9 \approx$ $\mathrm{pH}=3.4<\mathrm{pH}=4.4<\mathrm{pH}=6.0<\mathrm{pH}=7.3 \approx \mathrm{pH}=$ 8.0. Most notably, the best fit for the first shell for the samples at $\mathrm{pH}=2.0,2.9$, and 3.4 is obtained with four $\mathrm{O}$ atoms at a distance of $1.95 \AA$. At $\mathrm{pH}=4.4$, this distance has increased to $1.96 \AA$. For $\mathrm{pH}=6.0,7.3$, and 8.0, a distance of 1.98-1.99 $\AA$ was found, using $\mathrm{N}$ atoms in the fitting procedure. 


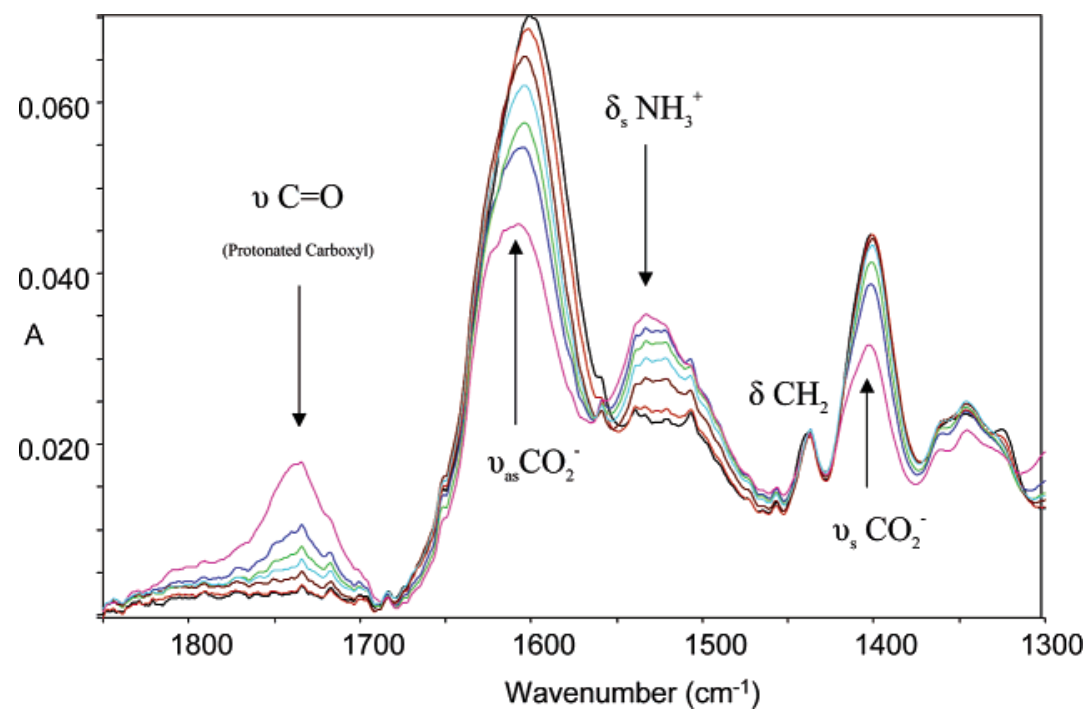

Figure 6. IR spectra of aqueous solutions of $0.25 \mathrm{M} \mathrm{Cu}^{2+} / \mathrm{his}$ at $\mathrm{pH}=1.95-3.55$. The arrows indicate the increasing $(\uparrow)$ and decreasing $(\downarrow)$ intensities at increasing $\mathrm{pH}$.

\section{Discussion}

A large amount of spectral data, covering a variety of spectral changes as a function of $\mathrm{pH}$, have been obtained from the different experiments. To systematically relate the data to (changes in) the geometrical structures of $\mathrm{Cu}^{2+} / \mathrm{his}$ complexes, the results will be discussed in subsections that represent the most important $\mathrm{pH}$ ranges.

pH Range of 0 - 2. The IR and Raman spectra of the $\mathrm{Cu}^{2+}$ / his solutions recorded up to $\mathrm{pH}=1.8$ appeared to be virtually identical with the ones of the his solutions at the same conditions. The presence of the $\mathrm{C}=\mathrm{O}$ and $\mathrm{C}-\mathrm{O}(-\mathrm{H})$ stretching bands in the IR spectra around bands at 1736 and $1257 \mathrm{~cm}^{-1}$, respectively, confirms that the carboxyl group is largely protonated, in accordance with the $\mathrm{p} K_{\mathrm{a}}$ of 1.8 . This implies that his is exclusively present as a free, noncoordinated ligand in the double-protonated ionic form, $\mathrm{H}_{4} \mathrm{his}^{2+}$. This is confirmed by the UV/vis/NIR data. The Cu solutions with his, him, and gly at $\mathrm{pH}=1$ exhibit the same $\mathrm{d}-\mathrm{d}$ transition band that is characteristic for $\mathrm{Cu}^{2+}$ surrounded by $\mathrm{O}$ atoms, i.e., as a hexa-aqua complex. The same conclusion can be drawn from the ESR data. It is known that the effect of the nuclear spin of $\mathrm{Cu}$ on the unpaired electron will be larger when the density of the d electron at the position of the $\mathrm{Cu}$ nucleus increases. When only $\mathrm{O}$ atoms are coordinating, the density of the unpaired paramagnetic electron at $\mathrm{Cu}^{2+}$ is at its minimum, which is accompanied by relatively high $g$ and low $A$ values compared to coordination by $\mathrm{N}$ atoms. The simulation of the ESR spectrum of the $\mathrm{Cu}^{2+} /$ his solution at $\mathrm{pH}=2$ indicates that about $85 \%$ of $\mathrm{Cu}^{2+}$ is present as a complex with relatively lowest $A$ and highest $g$ values (Table 1 ), and from the literature, it is known that these values are characteristic of the $\mathrm{Cu}$ hexa-aqua complex..$^{63}$ The same is concluded from the results of EXAFS. In accordance with

(61) Teo, B. K. EXAFS: Basic Principles and Data Analysis; SpringerVerlag: New York, 1986.

(62) Koningsberger, D. C.; Mojet, B. L.; van Dorssen, G. E.; Ramaker, D. E. Top. Catal. 2000, 10, 143-155.

(63) Szabo-Planka, T.; Rockenbauer, A.; Gyor, M.; Gaizer, F. J. Coord. Chem. 1988, 17, 69-83. the literature, a perfect fit is obtained with four $\mathrm{O}$ atoms from water in the first shell of the equatorial plane at a distance of $1.95 \AA{ }^{64}$

pH Range of 2-4. The first differences compared to the IR and Raman spectra of free his are observed at about $\mathrm{pH}$ $=2$. The changes in IR are well illustrated by the spectra recorded during titration from $\mathrm{pH}=1.95$ to 3.55 , as shown in Figure 6. The intensity of the $\mathrm{CH}_{2}$ scissoring band at 1440 $\mathrm{cm}^{-1}$ remains the same, but $v(\mathrm{C}=\mathrm{O})$ at $1736 \mathrm{~cm}^{-1}$ disappears. Concomitantly, two bands increase in intensity, i.e., the symmetric and antisymmetric stretching bands of the $\mathrm{CO}_{2}^{-}$group around 1402 and $1610 \mathrm{~cm}^{-1}$, respectively. These changes reflect the deprotonation of the carboxyl group with increasing $\mathrm{pH}$ and, as such, this behavior is identical with what we observed for free his. ${ }^{56}$ However, the position of $v_{\text {as }}\left(\mathrm{CO}_{2}{ }^{-}\right)$is about $10-15 \mathrm{~cm}^{-1}$ lower than that in the spectra of free his at the same $\mathrm{pH}$ value. Although a part of this shift can be attributed to deprotonation of the amino group, as will be pointed out later, the large downward shift must be the result of coordination of one of the carboxylate $\mathrm{O}$ atoms to the $\mathrm{Cu}^{2+}$ ion. ${ }^{65,66}$ The same conclusion has been reported by Kruck and Sarkar ${ }^{29}$ from the intensity decrease of the $1736-\mathrm{cm}^{-1}$ band at $\mathrm{pH}=2.5$ upon the addition of $\mathrm{Cu}^{2+}$, but it also illustrates that the conclusion of $\mathrm{Cu}^{2+} /$ his complex with a protonated carboxyl group as proposed by Meyer and Bauman ${ }^{53}$ is wrong. In accordance with the literature, ${ }^{65}$ the effect of metal coordination on $v_{\mathrm{s}}\left(\mathrm{CO}_{2}{ }^{-}\right)$ around $1402 \mathrm{~cm}^{-1}$ is much smaller. The Raman shift at around $560 \mathrm{~cm}^{-1}$, which rapidly increases in intensity at $\mathrm{pH}$ $>2$, has been proposed as additional evidence by Itabashi and Itoh. ${ }^{34}$ Indeed, a weak band at this position is also present in the spectrum at $\mathrm{pH}=1$, but this one probably originates from another vibration. These observations point to the

(64) Salmon, P. S.; Neilson, G. W.; Enderby, J. E. J. Phys. Chem. 1988, $21,1335-1349$

(65) Siiman, O.; Young, N. M.; Carey, P. R. J. Am. Chem. Soc. 1974, 96, $5583-5585$.

(66) Nakamoto, K.; Morimoto, Y.; Martell, A. E. J. Am. Chem. Soc. 1961, $83,4528-4532$. 


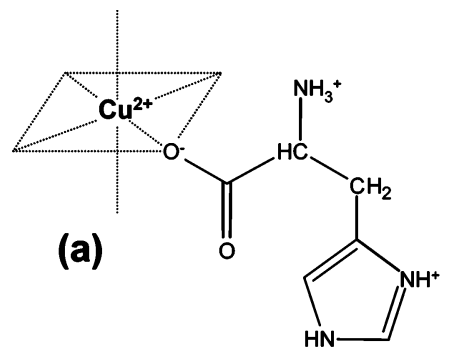

(c)

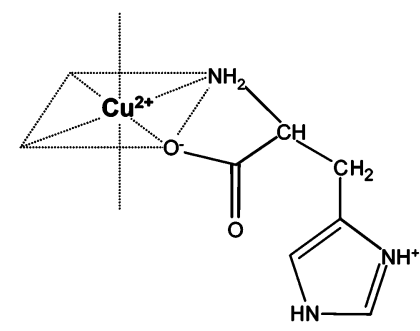

(e)

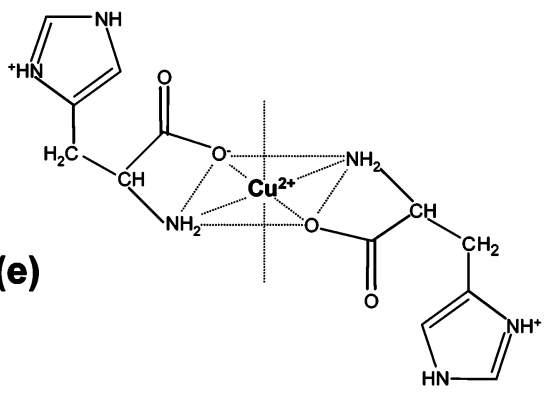

(g)

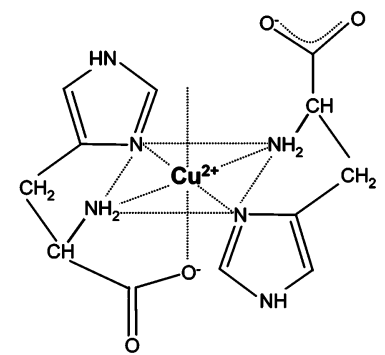

(b)

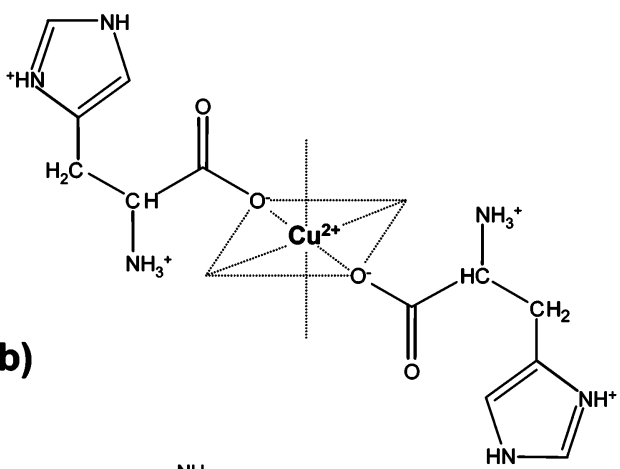

(f)

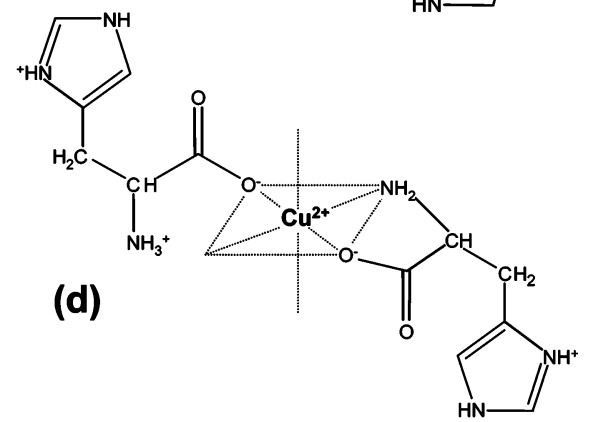

(h)

Figure 7. Proposed molecular structures of $\mathrm{Cu}^{2+} /$ his complexes at different $\mathrm{pH}$ values in the $\mathrm{pH}$ range of $0-10$. Coordination sites not occupied by his are occupied by water.

formation of complexes of the type $\mathrm{Cu}^{2+}\left[\mathrm{H}_{3} \mathrm{his}^{+}\left(\mathrm{O}_{\mathrm{c}}\right)\right]$ and $\mathrm{Cu}^{2+}\left[\mathrm{H}_{3} \text { his }^{+}\left(\mathrm{O}_{\mathrm{c}}\right)\right]_{2}$, depicted as structures a and $\mathrm{b}$ in Figure 7 , but closer examination of the IR spectra in Figure 6 shows that the intensity of the IR band at $1535 \mathrm{~cm}^{-1}$ decreases rapidly too upon an increase in the $\mathrm{pH}$. In the spectra of free his ${ }^{56}$ this absorption originates from the symmetric bending vibration of the protonated amino group $\left[\delta_{\mathrm{s}}\left(\mathrm{NH}_{3}{ }^{+}\right)\right]$, which normally loses its proton in accordance with the $\mathrm{p} K_{\mathrm{a}}$ at $\mathrm{pH}>9$. It follows that the accelerated deprotonation of the amino group must be the result of coordination of $\mathrm{N}_{\mathrm{am}}$ to $\mathrm{Cu}^{2+}$. The same can be concluded from the absorption band at around $1610 \mathrm{~cm}^{-1}$. This band consists of a peak from $\delta_{\text {as }}\left(\mathrm{NH}_{3}{ }^{+}\right)$at about $1620 \mathrm{~cm}^{-1}$ that partly overlaps the absorption of $v_{\mathrm{as}}\left(\mathrm{CO}_{2}^{-}\right)$at around $1600 \mathrm{~cm}^{-1}$. Upon an increase in the $\mathrm{pH}$, the contribution of $\delta_{\mathrm{as}}\left(\mathrm{NH}_{3}{ }^{+}\right)$decreases, and as a result, $v_{\text {as }}\left(\mathrm{CO}_{2}^{-}\right)$becomes the dominating component of the observed band. In principle, one might expect the appearance of an $\mathrm{NH}_{2}$ scissoring vibration in the same region, but as for the ionic states Hhis ${ }^{-}$and his ${ }^{2-}$ of free his, this absorption is weak and probably coincides with that of $v_{\text {as }}\left(\mathrm{CO}_{2}^{-}\right)$. Either way, the observed spectral changes can only be explained by assuming coordination of $\mathrm{N}_{\mathrm{am}}$ to $\mathrm{Cu}^{2+}$, which eliminates the dominating presence of a complex with $\left(\mathrm{O}_{\mathrm{c}}, \mathrm{N}_{\mathrm{im}}\right)$ coordination at this $\mathrm{pH}$, as has been proposed in several literature reports. ${ }^{32,38,54,67}$ It also follows that the previously mentioned complexes a and $\mathrm{b}$ must convert practically instantaneously to a bidentate complex, with $\mathrm{O}_{c}$ and $\mathrm{N}_{\mathrm{am}}$ as the coordinating anchors, such as in complexes $\mathrm{c}-\mathrm{e}$ (Figure 7). Clear vibrational spectroscopic differences between these complexes cannot be expected, and hence it

(67) Zhong, Z.; Postnikova, B. J.; Hanes, R. E.; Lynch, V. M.; Anslyn, E. V. Chem.-Eur. J. 2005, 11, 2385-2394. 


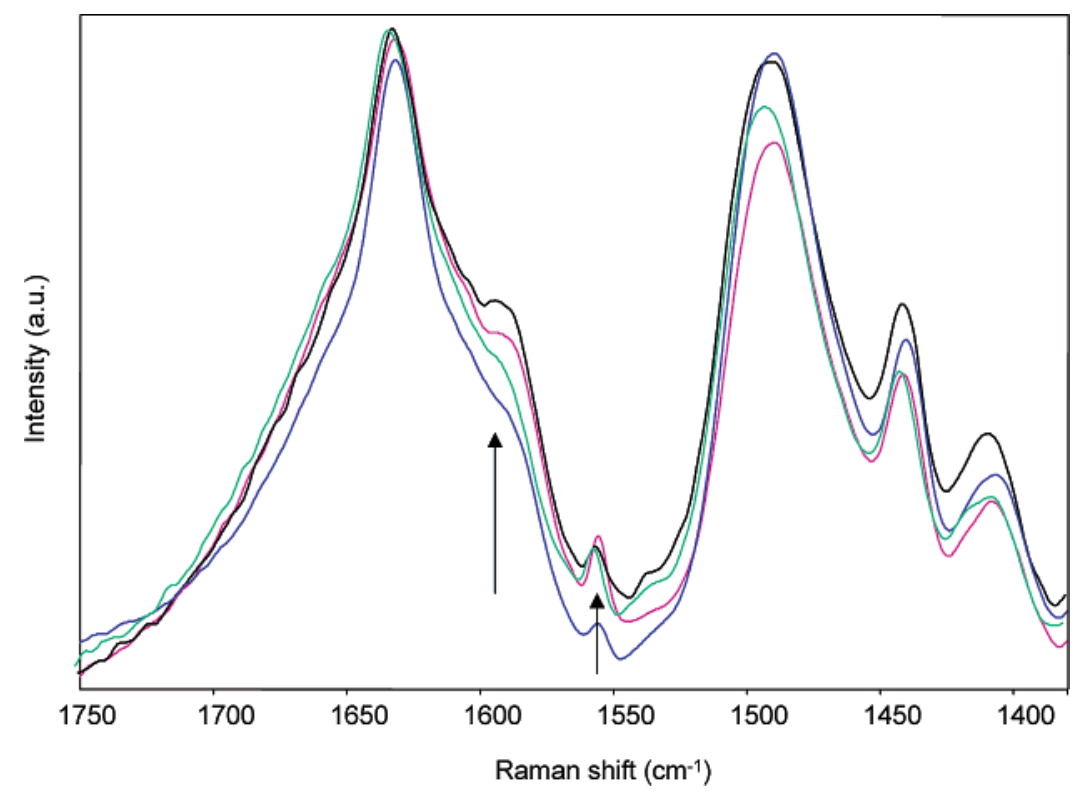

Figure 8. Raman spectra of $0.25 \mathrm{M}$ aqueous solutions of $\mathrm{Cu}^{2+} /$ his at $\mathrm{pH}=2.78,2.97,3.14$, and 3.47. The arrows indicate the appearance of bands at 1588 and $1555 \mathrm{~cm}^{-1}$.

is not possible to draw conclusions on their relative abundance. Most likely, in accordance with Itabashi and Itoh, ${ }^{34}$ the gly-like form $\mathrm{c}$ will be the major species at $\mathrm{pH}=$ 3. However, because all bands related to $\mathrm{C}=\mathrm{O}\left(1736 \mathrm{~cm}^{-1}\right)$ and $\mathrm{NH}_{3}{ }^{+}\left(1535 \mathrm{~cm}^{-1}\right)$ have disappeared at $\mathrm{pH}=4$, it is evident that free his is practically absent, and as a result, the complex $\mathrm{Cu}^{2+}\left[\mathrm{H}_{2} \mathrm{his}^{0}\left(\mathrm{O}_{\mathrm{c}}, \mathrm{N}_{\mathrm{am}}\right)\right]_{2}$ (structure e) must be the predominant species at this $\mathrm{pH}$. Most likely, the formation of this species proceeds via the intermediate form $\mathrm{d}$, but the lifetime of this complex will be negligibly short.

The shift of equilibrium from a complex with one his ligand to a structure with two his molecules is confirmed by the UV/vis/NIR and EXAFS data. EXAFS analysis reveals that there is no change in the distance of the first coordination sphere (Table S1 of the Supporting Information) and, thus, the observed shift of the UV/vis/NIR $d-d$ transition band to shorter wavelength must be the result of an increasing amount of coordinating $\mathrm{N}$ atoms in the equatorial plane as in the bidentate ligand complex e. Besides, the position of the $\mathrm{d}-\mathrm{d}$ transition band at $\mathrm{pH}=4$ is the same as that for $\mathrm{Cu}^{2+} / \mathrm{gly}$ in the $\mathrm{pH}$ range of $6-10$, in which the ligands are known to be coordinating via two $\mathrm{N}_{\mathrm{am}}$ and two $\mathrm{O}_{\mathrm{c}}$ atoms in the equatorial plane. Hence, it is logical to assume an $\mathrm{N}_{\mathrm{am}} \mathrm{O}_{\mathrm{c}} \mathrm{N}_{\mathrm{am}} \mathrm{O}_{\mathrm{c}}$-like coordination for $\mathrm{Cu}^{2+} /$ his at $\mathrm{pH}=4$. This conclusion is in agreement with the majority of the papers in the literature. ${ }^{10,29,30,34}$ The ESR results support these interpretations. The $\mathrm{Cu}$ hexa-aqua complex is about $85 \%$ at $\mathrm{pH}=2$ with $g_{0}$ and $A_{0}$ values that are characteristic of an $\mathrm{O}$ coordination sphere around $\mathrm{Cu}^{2+}$. The remaining $15 \%$ is of a complex(es) that becomes dominating $(75 \%)$ at $\mathrm{pH}=2.9$. The corresponding $g_{0}$ and $A_{0}$ parameters point to the coordination of one $\mathrm{N}$ atom, which is in line with the structures c and d (Figure 7). However, as stated before, we assume that the amino group coordinates to $\mathrm{Cu}^{2+} \mathrm{im}-$ mediately after coordination of the carboxyl group. This makes it very unlikely that structure $d$ is the dominating species at $\mathrm{pH}=2.9$ and, therefore, we conclude that the mono-his complex $\mathrm{c}$ is the major component.

The ESR parameters of the minor (25\%) species at $\mathrm{pH}=$ 2.9 are characteristic of complexes with two $\mathrm{N}$ atoms coordinating to $\mathrm{Cu}^{2+} .^{48} \mathrm{In}$ view of the preceding arguments, it is obvious that this must be the bis-his complex e, in which the two ligands are coordinating gly-like. Upon an increase in the $\mathrm{pH}$ to 3.4, the relative amount of the two complexes changes to a 55:45 (\%) mixture. Although we assume a considerable error in the calculated $\beta$ values (Table 1), the decrease from -1.6 at $\mathrm{pH}=2.0$ to -10 at $\mathrm{pH}=3.4$ is in agreement with this assignment because the decrease reflects a reduced tumbling velocity of the complex as a result of the increasing mass of the complexes upon converting from the hexa-aqua structure to the mono-his complexes and finally to the bis-his complexes.

Further information on the coordination geometry of the complexes is extracted from the Raman spectra (Figure 8). At $\mathrm{pH}=2.8$, two bands grow in at around 1555 and 1588 $\mathrm{cm}^{-1}$. The latter also shows up in the Raman spectra of free his but at much higher $\mathrm{pH}$ values. It has been assigned to coupled imidazole $\mathrm{C}=\mathrm{C} / \mathrm{C}=\mathrm{N}$ modes and is the result of deprotonation of the ring. ${ }^{56}$ For that reason, we assign the appearance of the bands at $1588 \mathrm{~cm}^{-1}$ in the spectra of $\mathrm{Cu}^{2+} /$ his as the result of coordination of (one of) the $\mathrm{N}_{\mathrm{im}}$ atoms, which is in agreement with literature reports. ${ }^{15,34}$ The involvement of the imidazole ring in the coordination can also be concluded from the prominent imidazole $=\mathrm{NH}$ deformation bands in the Raman spectra at 1490 and 1198 $\mathrm{cm}^{-1}$, which start to reduce in intensity at about $\mathrm{pH}=3.5$ instead of around $\mathrm{pH}=6$ in free his.

The coordination to the imidazole ring and the primary amino group at a $\mathrm{pH}$ significantly lower than the corresponding $\mathrm{p} K_{\mathrm{a}}$ values seems strange, particularly because repulsive forces will hamper the attraction between $\mathrm{Cu}^{2+}$ and the positively charged $\mathrm{NH}_{3}{ }^{+}$and imidazole ring. This implies 
that a $\mathrm{p} K_{\mathrm{a}}$ lowering mechanism must be the driving force. One explanation is that, upon coordination to $\mathrm{O}_{\mathrm{c}}$, the $\mathrm{Cu}^{2+}$ ion has an inductive effect on the ligand that promotes deprotonation and, hence, coordination of $\mathrm{N}_{\mathrm{am}}$ and $\mathrm{N}_{\mathrm{im}}$. Next, the fact that coordination to $\mathrm{N}_{\mathrm{am}}$ is favored over $\mathrm{N}_{\mathrm{im}}$ despite its higher $\mathrm{p} K_{\mathrm{a}}$ value can be attributed to either an energetically more stable geometry or a reduced inductive effect on $\mathrm{N}_{\mathrm{im}}$. The latter could be the result of the longer distance to the carboxylate group in combination with the resonance properties of the imidazole ring that will act as an electronic buffer. Another explanation has been reported very recently by Zhong et al. ${ }^{67}$ The authors also observed considerable $\mathrm{p} K_{\mathrm{a}}$ lowering effects induced by $\mathrm{Cu}^{2+}$ complexes and assigned these to an electrostatic interaction between the central $\mathrm{Cu}^{2+}$ ion and the anionic $\pi$ system of the ligands. Because inductive effects should have resulted in larger effects on the vibrational frequencies, we believe that the mechanism proposed by these authors is more plausible.

pH Range of 4-5. Upon an increase of the $\mathrm{pH}$ to 5 , the $\mathrm{UV} / \mathrm{vis} / \mathrm{NIR} \mathrm{d}-\mathrm{d}$ transition band shifts to $615 \mathrm{~nm}$, which is similar to the position of the $\mathrm{Cu}^{2+} /$ him complex at $\mathrm{pH}>7$, where the coordination is known to be $\mathrm{N}_{\mathrm{am}} \mathrm{N}_{\mathrm{im}} \mathrm{N}_{\mathrm{am}} \mathrm{N}_{\mathrm{im}}$ in the equatorial plane. The shift for $\mathrm{Cu}^{2+} /$ his can only be explained by a further increase in the number coordinating $\mathrm{N}$ atoms because the ligand field splitting for $\mathrm{N}$ atoms is larger than that for $\mathrm{O}$ atoms. ${ }^{59,60}$ This conclusion is endorsed by the results of EXAFS analysis, which show that the distance of the first coordination sphere around the $\mathrm{Cu}^{2+}$ ion remains unaffected. For that reason, we conclude that the predominant $\mathrm{N}_{\mathrm{am}} \mathrm{O}_{\mathrm{c}} \mathrm{N}_{\mathrm{am}} \mathrm{O}_{\mathrm{c}}$ coordination at $\mathrm{pH}=3.5$ starts to change into an $\mathrm{N}_{\mathrm{am}} \mathrm{O}_{\mathrm{c}} \mathrm{N}_{\mathrm{am}} \mathrm{N}_{\mathrm{im}}$ coordination around $\mathrm{pH}=4.5$ and subsequently into an $\mathrm{N}_{\mathrm{am}} \mathrm{N}_{\mathrm{im}} \mathrm{N}_{\mathrm{am}} \mathrm{N}_{\mathrm{im}}$ coordination at $\mathrm{pH}>5$. This is in line with most of the literature ${ }^{29,34,37,38,68}$ but proves that the assignment of Crawford and Dalton, ${ }^{46}$ who stated that $\mathrm{N}_{\mathrm{am}} \mathrm{O}_{\mathrm{c}} \mathrm{N}_{\mathrm{am}} \mathrm{O}_{\mathrm{c}}$ coordination remains the major structure up to $\mathrm{pH}=8$, is incorrect. According to the UV/vis/NIR data, $\mathrm{N}_{\mathrm{am}} \mathrm{N}_{\mathrm{im}} \mathrm{N}_{\mathrm{am}} \mathrm{N}_{\mathrm{im}}$ coordination appears to be almost complete already at $\mathrm{pH}=5$ because the position of the band almost matches that of $\mathrm{Cu}^{2+} / \mathrm{him}$ at $\mathrm{pH}>6$. The growing involvement of $\mathrm{N}$ atoms in the coordination also follows from a comparison of the ESR data recorded at $\mathrm{pH}=4.4$ and 3.4. The $g_{0}$ and $A_{0}$ parameters determined at $\mathrm{pH}=4.4$ clearly point to three $\mathrm{N}$ atoms in the coordination sphere of $\mathrm{Cu}^{2+}$. The corresponding complex(es) was calculated to cover $90 \%$ of the species present.

The IR and Raman data are in accordance with this conclusion. First, it is evident that $\mathrm{N}_{\mathrm{am}}$ remains coordinated to $\mathrm{Cu}^{2+}$ because the IR peaks related to the $\mathrm{NH}_{3}{ }^{+}$group remain absent in the spectra. Second, the Raman band at $1588 \mathrm{~cm}^{-1}$ rapidly gains intensity and, at $\mathrm{pH}=5$, it becomes even stronger than the one at $1632 \mathrm{~cm}^{-1}$, which illustrates the increasing number of coordinating $\mathrm{N}_{\mathrm{im}}$ atoms. The band at around $1588 \mathrm{~cm}^{-1}$ has also been reported in Raman studies on $\mathrm{Cu}^{2+}$ complexes with histidyl side-chain peptides ${ }^{3,16}$ and $\operatorname{him}^{33}$ and has been proposed to represent $\mathrm{N}^{\pi}-\mathrm{Cu}^{2+}$ ligation ( $\mathrm{N}^{\tau}$-protonated). Additional indications that $\mathrm{N}^{\pi}$ is the favored coordination site are extracted from the weak Raman band at $990 \mathrm{~cm}^{-1}$ and the IR absorptions at 1272 and $1087 \mathrm{~cm}^{-1}$. These bands are commonly used to distinguish the $\mathrm{N}^{\tau}$ protonated tautomer from the $\mathrm{N}^{\pi}$-protonated tautomer in the free ionic states $\mathrm{H}_{2}$ his $^{0}$ and $\mathrm{Hhis}^{-}$. In addition, the appearance of a broad $\mathrm{Cu}-\mathrm{N}$ stretching band at $454 \mathrm{~cm}^{-1}$ also points to coordination to $\mathrm{N}_{\mathrm{im}}{ }^{3,33}$ Furthermore, the IR spectra show the appearance of a weak band at $1506 \mathrm{~cm}^{-1}$ at around $\mathrm{pH}=4$, which is absent in the spectra of free his. It has been proposed as a marker for coordination to $\mathrm{N}^{\pi}$ in the spectrum of $\mathrm{Cu}^{2+}$ / him, ${ }^{33}$ but the corresponding vibrational mode is not clear.

Consequently, it seems logical to conclude that the increasing coordination of $\mathrm{N}_{\mathrm{im}}$ (i.e., $\mathrm{N}^{\pi}$ ) will be accompanied by a proportional release of carboxylate groups from the equatorial plane to the free form. However, the vibrational frequency of the IR-active $v_{\mathrm{as}}\left(\mathrm{CO}_{2}^{-}\right)$decreases to $1584 \mathrm{~cm}^{-1}$, while $v_{\mathrm{s}}\left(\mathrm{CO}_{2}^{-}\right)$increases from 1403 to $1408 \mathrm{~cm}^{-1}$. Indeed, the direction and magnitude of the shifts are similar to what we measured in the spectra of free his recorded in the same $\mathrm{pH}$ range, but the position of $v_{\mathrm{as}}\left(\mathrm{CO}_{2}{ }^{-}\right)$remains about 15 $\mathrm{cm}^{-1}$ lower. This implies that a substantial amount of the carboxyl groups must remain coordinated to $\mathrm{Cu}^{2+}$, either still in the equatorial plane or converted into the axial position. Therefore, we propose that the equatorial gly-like bidentate complex e starts to convert to the complex with tridentate ligands $\mathrm{Cu}^{2+}\left[\mathrm{Hhis}^{-}\left(\mathrm{O}_{\mathrm{c}}, \mathrm{N}_{\mathrm{am}}, \mathrm{N}_{\mathrm{im}}\right)\right]_{2}$ (Figure 7 , structure $\mathrm{h}$ ) with an equatorial him-like coordination for $\mathrm{N}_{\mathrm{am}}$ and $\mathrm{N}_{\mathrm{im}}$ and the carboxyl $\mathrm{O}_{c}$ atoms in the axial position. According to the ESR and UV/vis/NIR data, this process proceeds via the mixed bidentate/tridentate ligand complexes $\mathrm{f}$ and $\mathrm{g}$ as intermediates.

pH Range of 5-7. The data obtained at higher $\mathrm{pH}$ values confirm these conclusions but also reveal that a complex with $\mathrm{N}_{\mathrm{im}} \mathrm{N}_{\mathrm{im}} \mathrm{N}_{\mathrm{im}} \mathrm{N}_{\mathrm{im}}$ coordination around $\mathrm{pH}=6.5$, as proposed by Basosi et al., ${ }^{42}$ is unlikely. The increase of the $\mathrm{pH}$ from 5 to 7 is attended not only with an increase of the intensity of the UV/vis/NIR $d-d$ transition band but also with a shift back to longer wavelength. This is different from that of the $\mathrm{Cu}^{2+} / \mathrm{gly}$ and $\mathrm{Cu}^{2+} /$ him solutions, where the band remains unaffected. A plausible explanation for this phenomenon is that two $\mathrm{N}_{\mathrm{am}}$ atoms and two $\mathrm{N}_{\mathrm{im}}$ atoms start to coordinate in the equatorial plane on proceeding $\mathrm{pH}$, while the $\mathrm{O}_{\mathrm{c}}$ atoms convert from the equatorial plane to the axial position. This results in a decrease of the ligand field splitting because this parameter is also related to the distance of the orbitals of the $\mathrm{d}$ metal toward the atoms of the ligand. Besides, an increase in the axial $\mathrm{O}_{\mathrm{c}}$ coordination causes a distortion of the tetragonally elongated symmetry, which implies that the transition probability becomes larger and explains why the intensity of the $d-d$ transition band is enhanced. Finally, the observed red shift of the band confirms the distortion of the symmetry because the axial coordination of the carboxyl group(s) will cause an increase in the distance between the central $\mathrm{Cu}$ ion and the chelating atoms in the equatorial plane. This also follows from the EXAFS results, which reveal a small but significant increase in the distance of $\mathrm{Cu}^{2+}$ to the first coordination sphere from 1.96 to $1.99 \AA$ upon an increase in the $\mathrm{pH}$ from 4.4 to 7.3 . 
These conclusions confirm the conversion from the bidentate ligand complex e to the tridentate ligand form $h$, most likely via the mixed bidentate/tridentate ligand complexes $\mathrm{f}$ and $\mathrm{g}$ as intermediate forms. The coordination of $\mathrm{N}_{\mathrm{am}}$ and $\mathrm{N}_{\mathrm{im}}$ also follows from the vibrational spectra. For $\mathrm{N}_{\mathrm{am}}$, all bands related to the uncoordinated form remain absent, while the increasing coordination of $\mathrm{N}_{\mathrm{im}}$ can be extracted from the drop in the intensity of the Raman-active $=\mathrm{NH}$ deformation bands at 1492 and $1190 \mathrm{~cm}^{-1}$. Similar to free his, this intensity decrease is the result of the reduced symmetry of the imidazole ring by deprotonation of one of the $\mathrm{N}_{\mathrm{im}}$ atoms. Furthermore, a shoulder at around $1578 \mathrm{~cm}^{-1}$ arises on the Raman $\mathrm{C}=\mathrm{C} / \mathrm{C}=\mathrm{N}$ stretching band at $1588 \mathrm{~cm}^{-1}$. In accordance with the $\mathrm{p} K_{\mathrm{a}}$ value of the ring, two bands at around $1580 \mathrm{~cm}^{-1}$ are also observed in free his above $\mathrm{pH}=6$, and it therefore seems obvious to assign this shoulder to the formation of a complex with $\mathrm{N}^{\tau}$ coordination. However, according to the literature,,$^{3,15,16,33}$ the vibration that is correlated to $\mathrm{N}^{\tau}$ ligation ( $\mathrm{N}^{\pi}$-protonated) should be found at the high-frequency side instead of the low-frequency side of the $1588-\mathrm{cm}^{-1}$ band, i.e., at around $1603 \mathrm{~cm}^{-1}$. Besides, model calculations revealed that coordination to $\mathrm{N}^{\tau}$ is not attractive for sterical reasons. Consequently, we conclude that the coexistence of complexes with coordination to both $\mathrm{N}^{\tau}$ and $\mathrm{N}^{\pi}$, or a complex with both tautomeric forms coordinated to the same $\mathrm{Cu}^{2+}$, as suggested by Torreggiani et al., ${ }^{33}$ is unlikely. Another argument to reject two types of coordination of the $\mathrm{N}_{\mathrm{im}}$ atoms is the lack of doublets at around $1100 \mathrm{~cm}^{-1}$ in IR and at 1275 and $1000 \mathrm{~cm}^{-1}$ in Raman. Referring to the literature, , $, 31,33,36,68-70$ such double bands mark the presence of both tautomers, but only one band is observed in these regions. The presence of one tautomeric form is further evidenced by the small bandwidth of the Raman-active ring-breathing vibration at $1273 \mathrm{~cm}^{-1}$. This peak is considerably sharper than what we observed in the Raman spectra of free his, which points to a single rigid structure of the ring, i.e., only one type of $\mathrm{N}_{\mathrm{im}}$ coordination. To explain the presence of the band at around $1578 \mathrm{~cm}^{-1}$, we propose two possibilities: (1) the metal coordination of the ring results in decoupling of the combined $\mathrm{C}=\mathrm{C} / \mathrm{C}=\mathrm{N}$ vibration, which gives rise to separate $\mathrm{C}=\mathrm{C}$ and $\mathrm{C}=\mathrm{N}$ stretching modes and (2) two $\mathrm{N}^{\pi}$-ligated complexes are present that only differ in their symmetrical orientation toward the $\mathrm{Cu}$ ion. The origin of the weak Raman band that comes up at $1555 \mathrm{~cm}^{-1}$ is not clear, but its appearance matches the explanation of decoupling because in this region only $\mathrm{C}=\mathrm{C}$ and/or $\mathrm{C}=\mathrm{N}$ stretching modes are present. Finally, the fact that only one Raman band arises at $1228 \mathrm{~cm}^{-1}$ can also be attributed to the deprotonation of only one of the $\mathrm{N}_{\mathrm{im}}$ atoms, similarly in free his. ${ }^{56}$

pH Range of 7-10. The spectral changes in ESR, IR, Raman, UV/vis/NIR, and EXAFS in the $\mathrm{pH}$ range of $7-10$ are relatively small compared to the data collected at $\mathrm{pH}=$

(68) Williams, D. R. J. Chem. Soc., Dalton Trans. 1972, 790-797.

(69) Toyoma, A.; Ono, K.; Hashimoto, S.; Takeuchi, H. J. Chem. Phys. A 2002, 106, 3403-3412.

(70) Ashikawa, I.; Itoh, K. Biopolymers 1979, 18, 1859-1876.

(71) Noguchi, T.; Inoue, Y.; Tang, X. S. Biochem. 1999, 38, 10187-10195.
6, which confirms that structure h (Figure 7) has become the predominant complex at neutral and basic conditions. In accordance with this, simulation calculations on the ESR spectrum at $\mathrm{pH}=7.3$ clearly point to the dominating presence of a single $\mathrm{Cu}$ complex, and the high $A_{0}$ and low $g_{0}$ values as well as the fitted $\beta$ value of $-10 \mathrm{G}$ are fully in line with the bis-his structure of this complex. The consistent $\beta$ value also indicates that the formation of a much larger binuclear $\mathrm{Cu}^{2+} /$ his complex, as proposed in the literature, ${ }^{29}$ is not very likely, at least at this $\mathrm{pH}$.

In line with the conversion to complex h, the UV/vis/NIR absorption band recorded at $\mathrm{pH}=7$ is slightly red-shifted compared to the position at $\mathrm{pH}=6$ but stabilizes at higher $\mathrm{pH}$, indicating that this process is practically completed at $\mathrm{pH}>7$. The same can be concluded from the increasing intensity, which is consistent with the results from EXAFS and ESR. Indeed, a further intensity enhancement is observed at $\mathrm{pH}>7$, but this can be attributed to the formation of copper hydroxide/oxide species, as pointed out in the Experimental Section. It also explains why Perrin and Sharma ${ }^{50}$ and Sigel et al. ${ }^{38}$ erroneously assumed the presence of $\mathrm{Cu}^{2+}(\mathrm{OH}) /$ his complexes at $\mathrm{pH}>7$.

Although the changes in the vibrational spectra are small, important information on the coordination of the $\mathrm{CO}_{2}{ }^{-}$group can be extracted from the $v_{\mathrm{as}}\left(\mathrm{CO}_{2}^{-}\right)$band at $1584 \mathrm{~cm}^{-1}$ in IR. In contrast to free his, where we observed a continuous red shift to $1564 \mathrm{~cm}^{-1}$ upon an increase in the $\mathrm{pH}$ to 10 , the band remains fixed at $1584 \mathrm{~cm}^{-1}$. In our opinion, this confirms that the carboxyl group remains coordinated to $\mathrm{Cu}^{2+}$. Furthermore, the bandwidth is significantly smaller compared to, e.g., $\mathrm{pH}=4$ and 5, which can be considered as a change from a mixture of equatorially and axially coordinated $\mathrm{CO}_{2}{ }^{-}$at low $\mathrm{pH}$ to a single fixed axial position at $\mathrm{pH}>7$, thus proving that reorientation into the axial position is completed. The simultaneous disappearance of the Raman band at $560 \mathrm{~cm}^{-1}$, which has been assigned to a $\mathrm{Cu}-\mathrm{O}$ vibration in the equatorial plane, ${ }^{34}$ can be seen as additional evidence for the correctness of this assignment. Finally, the enhanced intensity of the Raman doublet at around $1580 \mathrm{~cm}^{-1}$ on the cost of the $\mathrm{C}=\mathrm{C} / \mathrm{C}=\mathrm{N}$ band at $1632 \mathrm{~cm}^{-1}$ indicates that all of his has become coordinated to $\mathrm{Cu}^{2+}$ through $\mathrm{N}^{\pi}$, which is confirmed by the increased intensity of the $\mathrm{Cu}-\mathrm{N}$ stretching band at $454 \mathrm{~cm}^{-1}$. It follows that the double-tridentate ligand complex $\mathrm{h}$ is indeed the major species at high $\mathrm{pH}$, whereas bidentate geometries are probably no longer present.

Complex Distribution. The large number of IR spectra, extracted from the titration experiments, allowed MCR calculations to obtain a quantitative distribution plot of the complexes as a function of the $\mathrm{pH}$. The relative abundances of the different complexes as derived from ESR, UV/vis, and EXAFS have been used as additional input to enhance the reliability and accuracy of the plot. The result of the MCR calculations, of which details are given in the Supporting Information, is shown in Figure 9. The distribution plot slightly differs from the one proposed by Sarkar and coworkers, ${ }^{18,19}$ but as demonstrated, the large number of complementary spectroscopic data produced in our study not 


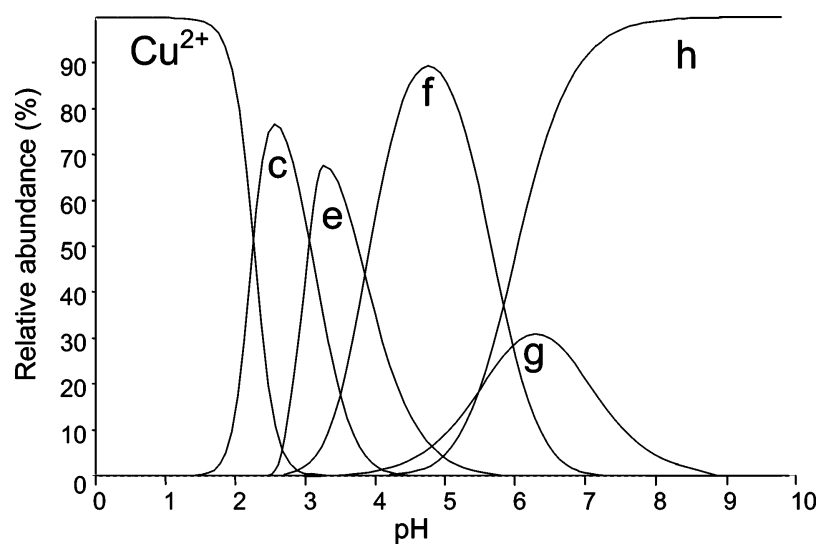

Figure 9. Proposed distribution of $\mathrm{Cu}^{2+} /$ his complexes as a function of the $\mathrm{pH}$ of the solution. Complexes $\mathrm{c}$ and $\mathrm{e}-\mathrm{h}$ correspond to the structures depicted in Figure 7. Complexes a, b, and d are supposed to be absent or present below the limit of detection.

only can be used to determine the coordination and ionic states of the his ligands but also admits further refinement in distinguishing the different geometrical orientations within each state of protonation in a quantitative way. Six complexes evidently appear to be present, i.e., $\mathrm{Cu}\left(\mathrm{H}_{2} \mathrm{O}\right)_{6}{ }^{2+}$ and complexes $\mathrm{c}$ and $\mathrm{e}-\mathrm{h}$, while three complexes, i.e., $\mathrm{a}, \mathrm{b}$, and $\mathrm{d}$, have not been detected. However, this is in line with what was expected.

\section{Conclusions}

The combined application of IR, Raman, UV/vis/NIR, ESR, and XAS proves to be crucial to obtaining consistent and complementary information on the geometrical structures and relative abundances of $\mathrm{Cu}^{2+} /$ his (1:2) complexes in an aqueous solution as a function of the $\mathrm{pH}$. Although intrinsic instrumental limitations hampered spectroscopic analysis at identical concentration levels, thus limiting the accuracy of the overall conclusions, the experimental conditions have shown to be a fair compromise. The results from UV/vis/ NIR and ESR fully agree on the nature of the atoms in the first coordination shell of the $\mathrm{Cu}^{2+}$ ion, while EXAFS adds knowledge on the average distance between the coordinating atoms and the central $\mathrm{Cu}^{2+}$ ion. IR and Raman produce detailed complementary information on the state of protonation of the his ligands and, hence, on the sites involved in the coordination to $\mathrm{Cu}^{2+}$. As a result, structural proposals from the literature have been unambiguously confirmed, clarified, or corrected where necessary.

It was found that the complex formation process is reversible as long as the $\mathrm{pH}$ does not exceed a value of 10 . At higher $\mathrm{pH}$, decomposition and precipitation of $\mathrm{Cu}^{2+} /$ his complexes occurs. At $\mathrm{pH}<2$, both $\mathrm{Cu}^{2+}$ and his are present as free ions. The formation of complexes starts at around the $\mathrm{p} K_{\mathrm{a}}$ value of the carboxyl group, i.e., at $\mathrm{pH}=1.8$, by anchoring an $\mathrm{O}$ atom in the equatorial plane (complexes a and b). Concomitantly, coordination via the amino group begins, which results in a bidentate gly-like chelation with mainly one ligand (complex c). At around $\mathrm{pH}=3$, this complex is the major constituent. Coordination of a second his molecule rapidly follows, and at $\mathrm{pH}=4$, the bidentate ligand complex e is the dominant species. The Raman data show that coordination to the $\mathrm{N}^{\pi}$ atom of the imidazole ring starts at around $\mathrm{pH}=2.8$ and, at around $\mathrm{pH}=5$, complex $\mathrm{f}$ with equatorial him-like coordination via the $\mathrm{N}_{\mathrm{am}}$ and $\mathrm{N}^{\pi}$ atoms becomes the main component. This reorientation of the his ligand is not attended with the release of the carboxyl group to the nonbonded state, but according to IR, the coordination of the $\mathrm{O}$ atom converts from the equatorial plane to the axial position. This conversion continues via complex $\mathrm{g}$ to the double-tridentate ligand complex $\mathrm{h}$ with four $\mathrm{N}$ atoms in the equatorial plane and two carboxyl $\mathrm{O}$ atoms in the axial position as the dominant geometrical structure at $\mathrm{pH}>7$. This structure remains stable up to $\mathrm{pH}=10$ and decomposes at higher solution $\mathrm{pH}$.

Finally, it is concluded that the $\mathrm{p} K_{\mathrm{a}}$ value is not the primary driving force in the coordination process. After deprotonation and anchoring to the carboxyl group in accordance with its $\mathrm{p} K_{\mathrm{a}}$ value (1.8), coordination to $\mathrm{N}_{\mathrm{am}}$ and $\mathrm{N}_{\mathrm{im}}$ atoms occurs at around $\mathrm{pH}=3$ and 5, respectively. This is in a different order and at significantly lower $\mathrm{pH}$ than could be expected on the basis of the $\mathrm{p} K_{\mathrm{a}}$ values of these $\mathrm{N}$ groups. The effect is assigned to an electrostatic interaction between the central $\mathrm{Cu}^{2+}$ ion and the anionic $\pi$ system of the his ligands.

Acknowledgment. Financial support from NWO/CWVan der Leeuw, National Research School CombinationCatalysis (NRSC-C), and NWO/CW-VICI is kindly acknowledged. The authors are also indebted to Mettler Toledo (Autochem) for the use of the React-IR 4000 system and to Robert Schoonheydt for the ESR facilities at KU Leuven (Leuven, Belgium). The European Synchrotron Radiation Facility (ESRF) is acknowledged for the provision of its synchrotron radiation facilities. We thank S. Nikitenko of DUBBLE (BM26a, ESRF) for his help during the experiments.

Supporting Information Available: IR, ESR, and Raman spectra of $\mathrm{Cu}^{2+} /$ his at various $\mathrm{pH}$ values; ESR, XAFS, and MCR analyses; and Fourier transforms. This material is available free of charge via the Internet at http://pubs.acs.org.

IC051305N 